Article

\title{
Sustainable and De-Stressed International Supply-Chains Through the SYNCHRO-NET Approach
}

\author{
Riccardo Giusti ${ }^{1}$, Chiara Iorfida ${ }^{2}$, Yuanyuan Li ${ }^{3}$, Daniele Manerba ${ }^{1,4}, *\left(\mathbb{D}\right.$, Stefano Musso ${ }^{1,4}(\mathbb{D}$, \\ Guido Perboli ${ }^{1,4,5}\left({ }^{1}\right.$, Roberto Tadei ${ }^{1}(\mathbb{D})$ and Shuai Yuan ${ }^{1}$ \\ 1 Department of Control and Computer Engineering, Politecnico di Torino, corso Duca degli Abruzzi 24, \\ 10129 Turin, Italy; riccardo.giusti@polito.it (R.G.); stefano.musso@polito.it (S.M.); \\ guido.perboli@polito.it (G.P.); roberto.tadei@polito.it (R.T.); shuai.yuan@polito.it (S.Y.) \\ 2 COSCO SHIPPING Lines (Spain) S.A., Carrer de Casanova 2, E-08011 Barcelona, Spain; \\ chiara.iorfida@coscospain.com \\ 3 Fondazione LINKS, via Pier Carlo Boggio 61, 10138 Torino, Italy; yuanyuan.li@linksfoundation.com \\ 4 ICT for City Logistics and Enterprises (ICE) Lab, Politecnico di Torino, Corso Duca degli Abruzzi 24, \\ 10129 Turin, Italy \\ 5 Centre Interuniversitaire de Recherche sue les Réseaux d'Entreprise, la Logistique et le Transport (CIRRELT), \\ Montréal, QC H3C 3J7, Canada \\ * Correspondence: daniele.manerba@polito.it; Tel.: +39-011-090-7012
}

Received: 21 December 2018; Accepted: 14 February 2019; Published: 19 February 2019

\begin{abstract}
Synchro-modal supply chain eco-NET (SYNCHRO-NET) is a Horizon 2020 European research project aimed at overcoming the stress due to the increasing transportation distances, the higher complexity, and the vulnerability of international supply chains. In order to foster sustainability, quality, and reliability of such supply chains, SYNCHRO-NET mainly exploits the impact and the possible benefits coming from slow/smart-steaming and synchro-modality transportation strategies, and the related business models. The aim of this paper is to summarize and disseminate the main developments and scientific contributions coming from the project. In particular, the working core of the SYNCHRO-NET solution is an integrated and cloud-based eco-system of optimization and simulation software modules that supports stakeholders' decisions in freight transportation and logistics management at strategic, operational, and real-time levels. The platform has achieved a high grade of automation in several processes to overcome all the issues related to human-based operations. The efficiency and effectiveness of the overall platform have been tested on three case studies considering pan-European and regional trade lanes, as well as commercial activities between the Far East and European ports. The project results and outputs also allow us to analyze barriers and opportunities of the approach, industrial and academic developments, and relations with emerging technologies.
\end{abstract}

Keywords: SYNCHRO-NET; freight transportation; synchro-modality; de-stressing; smart-steaming; cloud-platform

\section{Introduction}

In recent years, the importance of effectiveness and efficiency in freight transportation increased, due to the increasing growth of international trade volumes. The World Trade Organization (WTO) measured a $2.4 \%$ growth for the trade volumes in 2017, and growth is expected to continue until 2020 [1]. Considering containerized goods, global container trade volumes increased from 69 million TEUs in 2000 to 171 million TEUs in 2014, with an annual average increase of almost 7\% (despite the global economic downturn during the second half of this period) [2]. Moreover, European Union 
statistics show a range from $24 \%$ to $28 \%$ for empty vehicle running, and capacity utilization by weight ranging from $54 \%$ to $57 \%$ over a ten-year period [3].

Environmental issues are gaining importance in the logistics field, due to the increasing demand of the mobility of goods. Environmental sustainability is becoming an important selection criterion for firms operating in the logistics sector, and a critical success factor in terms of cost reduction (in terms of access to financial incentives and increasing demand for green products and services) [4]. In this context, the Synchro-modal supply chain eco-NET (SYNCHRO-NET) project is one of the largest projects funded by the Horizon 2020 Programme, with the aim to optimize the supply chain through the adoption of environmentally friendly practices in long-haul container shipments. In particular, synchro-modality and slow/smart steaming are two objectives of the SYNCHRO-NET project, widely recognized as drivers for the reduction of costs and pollution. Slow-steaming is the practice of operating cargo ships at significantly less than their design speed, reducing fuel costs and GHG emissions, while smart-steaming is a way to manage ship speeds in order to optimize the overall supply-chain [5,6]. Synchro-modality, instead, is an inter/multi-modal transportation concept in which stakeholders can switch between modes in real time for higher efficiency [7].

The ambition of the European Community to foster the synchro-modality, and in particular the modal shift from road to rail, needs the introduction of innovative solutions supporting the integration of different transport modes. The consortium is led by DHL Exel Supply Chain Spain and includes technical partners, research institutions, and key stakeholders in the freight logistics sector. Politecnico di Torino is the technical and scientific responsible of the project.

The following two research questions have mainly guided the SYNCHRO-NET project and the writing of the present paper:

- $\quad$ RQ1: Is it possible to have true (operationally, socially, environmentally) sustainable systems?

- RQ2: Which barriers must a system like SYNCHRO-NET take into account and try to overcome? Which opportunities, coming from the most recent technologies, should be exploited?

This paper gives a first answer to these questions by summarizing and disseminating the main developments and the scientific contributions coming from the SYNCHRO-NET project. Moreover, it reports the experimental results obtained through three different real-case demonstrators. In fact, all the tools developed within the SYNCHRO-NET project have been tested in realistic scenarios in order to evaluate the impact of the adoption of environmentally sustainable solutions. The proposed solutions have been tested using different Key Performance Indicators (KPIs) such as time, distance, and emissions, Key Risk Indicators (KRIs) such as safety, flexibility, cost and time reliability, and compared with the best practices of companies worldwide recognized as leaders in the field. Finally, the project results and outputs also allow us to analyze the barriers and the opportunities of the approach, industrial and academic developments, and relations with emerging technologies.

\section{Literature Review}

The interest in more sustainable approaches to freight logistics, including aspects such as synchro-modality and slow-steaming, is rapidly growing in recent years. In particular, the importance of these solutions relies on their capability to reduce both operational costs and environmental externalities [5,6]. Recently, different studies have been conducted with the objective to show the potential benefits of operational optimization and synchro-modality in the transportation sector. e.g., the important role of rail in the development of competitive and sustainable transport systems for medium and long-haul shipments is highlighted in [8]. In particular, the main benefits of rail are the lower negative externalities than road transport and the use of green energy sources. Moreover, the ever-increasing size of the container ships is increasing the concentration of freight volumes in ports, with impacts on the operational efficiency and on the inland transport network. In this context, the need to optimize the freight flows can foster the adoption of synchro-modal solutions and the modal shift from truck to rail. In a literature review covering works from 1960 to 2014 [4], it is 
highlighted that the factors most influencing the adoption of green initiatives in the transportation and logistics sector are the pressure of regulations and the market competitiveness. It is therefore clear that both public regulations and market dynamics are responsible for the growth of environmental sustainable transport systems. In the same study, authors also highlight that regulations and standards are also seen as barriers affecting the adoption of green initiatives, along with investment costs, in particular for medium and small operators. Similarly, in another paper investigating the significant factors influencing the adoption of green practices within logistics companies [9], it is shown how compliance with governmental regulations is one of the main factors influencing the adoption of green logistics practices, in particular in developed countries. At the same time, alternative energies and synchro-modality are presented as the main opportunities for logistics companies to enhance their competitiveness.

Concerning the importance of a collaborative network between logistics companies, one of the main factors of inefficiency in freight transportation is related to a high percentage of empty running and low load factors [10]. In this context, companies working in a collaborative network are able to achieve higher vehicle capacity utilization and reduce empty running, with positive effects in terms of costs and sustainability (lower emissions and road congestion). Moreover, the collaboration within the network increases the freight volumes, with positive impacts on the overall efficiency. In fact, the growth of international trade and cargo demand puts under pressure the current infrastructural capacity, with negative impacts on congestion, safety, and environment [11]. In this perspective, the evolution of synchro-modal transport systems is a great opportunity to improve the sustainability of freight transport, through a modal shift from truck to rail.

Synchro-modality and slow-steaming are considered very important in the European Commission's research agenda and highly supported through funding for research and development, and by the European Technology Platform ALICE [12]. For this reason, other similar projects have been developed in recent years. As already analyzed in [13], it is possible to find two complete and successful projects, that are also quite similar to SYNCHRO-NET: European e-Freight Capabilities for Co-modal Transport (e-FREIGHT: https:/ / trimis.ec.europa.eu/project/european-e-freight-capabilities-co-modal-transport, accessed: 25 January 2019) and e-Maritime Strategic Framework and Simulation based Validation (eMAR: http:/ /www.emarproject.eu/, accessed: 25 January 2019). The aim of the e-FREIGHT project was to develop an intelligent cargo solution in order to connect goods to a wide range of information services, thus creating an automated freight transportation management process. The aim of the eMAR project was to support the development of sustainable maritime transport in Europe through the definition of a framework based on the latest information, communication, and surveillance technologies. The analysis of these projects highlights how the research was focused mainly on technical, ICT, and optimization issues, without considering the actual business models of the involved stakeholders, with the risk to develop technical solutions that are not matching with the industrial needs. Instead, by involving industrial partners (as stakeholders and Advisory Board's members) in the development of the solutions, SYNCHRO-NET proposes to address the issue of cooperation between all relevant aspects (not restricted to ICT) by promoting new forms of collaboration and stimulating the introduction of innovative collaborative business models across Europe (see Section 3). In particular, it adopts a stakeholder-driven methodology where the requirements and feedbacks of potential end-users in the industry drive the development of the prototypes tested in business case demonstrators.

Finally, the study of synchro-modal settings and the relative optimization methodologies seem still at an early stage and very few contributions go beyond conceptual issues. Consequently, there is also a lack of applicative solutions/tools able to exploit the potentialities of synchro-modal transportation in realistic commercial contexts. The proposed solutions (see, e.g., $[14,15])$ tend to only consider a single mode, a limited geographical area, or a specific issue (empty container repositioning, berth scheduling in ports, rail capacity). Furthermore, these systems are generally driven by an over-simplified cost model. Other existing platforms that can be found as online commercial services (e.g., www.inttra.com 
or www.searates.com) are in general oriented entirely to pricing and booking details. SYNCHRO-NET, instead, aims at supporting companies in improving their business through the use of better solutions in terms of cost, time, distance, sustainability, flexibility, and emissions.

\section{The SYNCHRO-NET Vision: A Sustainable Business Model}

In recent years, the transportation industry has become an important pillar for the development of countries, as a key to guaranteeing employment, procurement for companies, social welfare, as well as the dynamism and the growth of economies. Furthermore, the relationship between freight transportation demand and economic growth is two-way: not only does this phenomenon affect the increased demand for shipping services, but also the efficiency of the transport sector in the handled goods that is a necessary requirement to economic growth. Under this perspective, the concept of transport needs to be promoted as an integrated process of transfer of goods through the use of different modes.The freight transport environment is made by a complex network of stakeholders with often conflicting visions and incentives, sharing the common goal of making efficient transport. Moreover, there is the need of the interoperability of both logistics and ICT sectors, in order to develop Intelligent Transport Systems (ITS) with the aim to increase the efficiency, competitiveness, safety, and sustainability of the transport system.

Concerning the technical aspect, the objective of the SYNCHRO-NET project is to develop an optimization tool set able to implement both synchro-modality and slow steaming strategies, in order to show that the combined application of these two strategies can lead to potential benefits for all the actors involved in the supply chain. The project adopts a stakeholder-driven approach, starting from the analysis of needs and requirements of the different actors involved in the supply chain. Taking into account the actual needs of the stakeholders and potential customers, and involving them in the development phase, will foster the large-scale adoption of the proposed solution. In particular, the stakeholder requirements have been analyzed (through a survey) from the early stages of the development, in order to meet the stakeholders' needs in terms of business model and operational aspects, leading to higher market acceptance of the solutions. Moreover, the prototypes developed in the project have been tested in business case demonstrators, and the resulting feedback has been used to refine and enhance the subsequent prototypes.

The value proposition of the SYNCHRO-NET project [13] consists of a single platform, in which all the actors involved in the supply chain can interact to optimize and synchronize operations. One of the main benefits of planning and monitoring the supply chain with a single tool is the increase of communication and information exchange among the different actors, with a consequent increase in the service provided in terms of quality and reliability. Moreover, the increase in service reliability means more reliable delivery times for firms, allowing a reduction of buffer stocks. The long-term optimization of the supply chain process leads to more efficient resource usage for logistics operators and port authorities, allowing better working conditions for workers. For public authorities, an optimized planning and monitoring process leads to better control over infrastructure usage, preventing congestion and bottlenecks. The synchronization between different transport modes can be a driver to foster the adoption of lower-emissions modes, thus reducing the impact on the environment, and enhancing the image of firms and logistics operators. Moreover, an optimized synchronization between different transport modes could foster the adoption of slow steaming strategies for ships and trucks, also with a positive impact on the environment.

Figure 1 shows the Business Model Canvas of the SYNCHRO-NET project. 


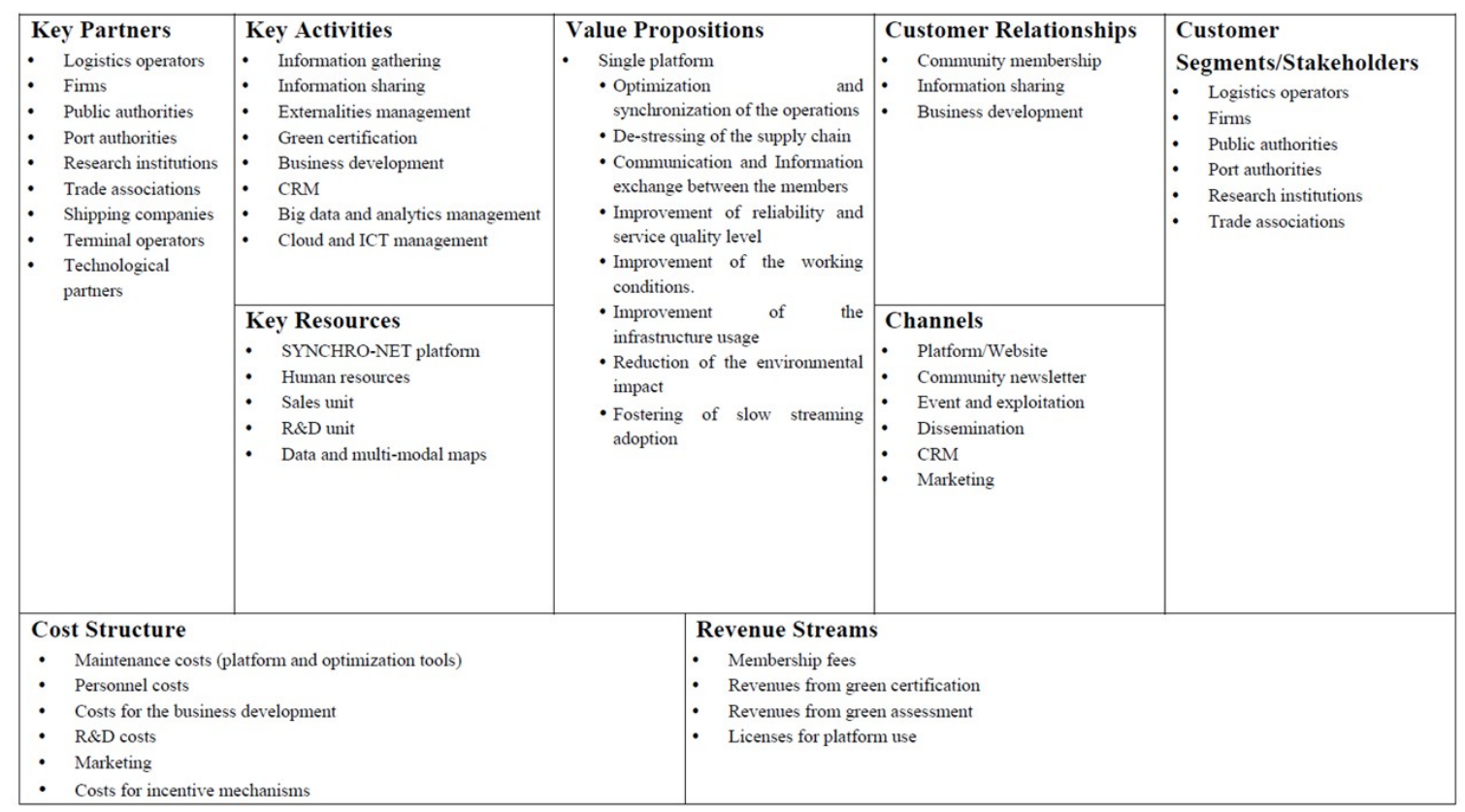

Figure 1. Business model canvas of the SYNCHRO-NET project.

As already stated, the value proposition of the project is to provide a single platform enabling the management of all the different processes related with the freight transport, allowing the customers to evaluate different strategic scenarios (using the simulation tools) and to book and monitor actual shipments. The customer segments and stakeholders are both public and private, and they share the common objective related with a more effective, efficient, and safe management of the logistics operations (firms, trade associations, and logistics operators), and to track in a more effective way the flow of goods through ports, terminals, and infrastructures (public and port authorities). The stakeholders and potential customers of the project are the same ones that have been involved as key partners, since one of the strengths of the project is the involvement of the potential users in the entire process. The cost structure of the SYNCHRO-NET project considers different sources of costs, from the maintenance and personnel costs to the business development, $R \& D$, and marketing costs for the commercialization phase. Moreover, the cost structure includes also the implementation of incentive mechanisms in order to increase the interest of potential users and thus to reach a critical mass. One of the main expected revenue streams relies on the membership fees, and, for this reason, it is important to build an effective pricing strategy, considering different pricing levels (also to engage small and medium enterprises). Other expected sources of revenue come from the green assessment certification of external supply chains, and from licenses for the platform use.

\section{The SYNCHRO-NET Software Platform}

The overall SYNCHRO-NET solution has its foundation on and finds its concretization in an integrated software eco-system, supporting the synchro-modal freight logistics at different levels and for different users' needs. Its main functionalities range from the harvesting and management of valuable data for the process to an extensive decision support through simulation, optimization, and monitoring of the involved operations [16].

In this section, we will describe all the main characteristics of the developed platform. Section 4.1 provides an overall vision on the logical and functional architecture of the system. Sections 4.2 and 4.3 describe the strategic simulation/optimization toolset and the simulation-based risk analysis module, respectively. In Section 4.4, the real-time features of the system are explained with a particular focus on the re-optimization routines able to overcome unforeseen events during a shipment. Section 4.5 gives 
a brief explanation on how the Maritime Cloud works and which is its role in the whole system. Finally, Section 4.6 focuses on the user configuration functionalities and on the Stakeholder Assessment process.

\subsection{A Collaborative Cloud-Based Eco-NET}

In order to really achieve cost-effective robust solutions that de-stress the supply-chain guaranteeing the reduction of emissions and costs for logistics operations, the SYNCHRO-NET project incorporates into a single software platform strategic and real-time synchro-modal logistics optimization, smart-streaming ship simulation, control and piloting, risk/benefits analysis, stakeholder impact assessment, and synchro-operability communications. The resulting innovative system, called eco-NET, has been designed as a collaborative cloud-based eco-system by Software AG, in collaboration with Circle (partners of the consortium).

Figure 2 presents an overview of the entire platform architecture and shows, in a unified way and independently from the implementation technologies, all functional and non-functional aspects of the developed system. In order to achieve a maximum degree of flexibility for platform deployments and to facilitate information transport, a Service-Oriented Architecture (SOA) paradigm has been used, including message handling capabilities and typical cloud-oriented concepts. The cloud provides connectivity and protocols to communicate internally and, potentially, with related external systems. The integration with external services is done by using standardized and open APIs, which allow accessing the functionalities of specific modules representing the platform's core.

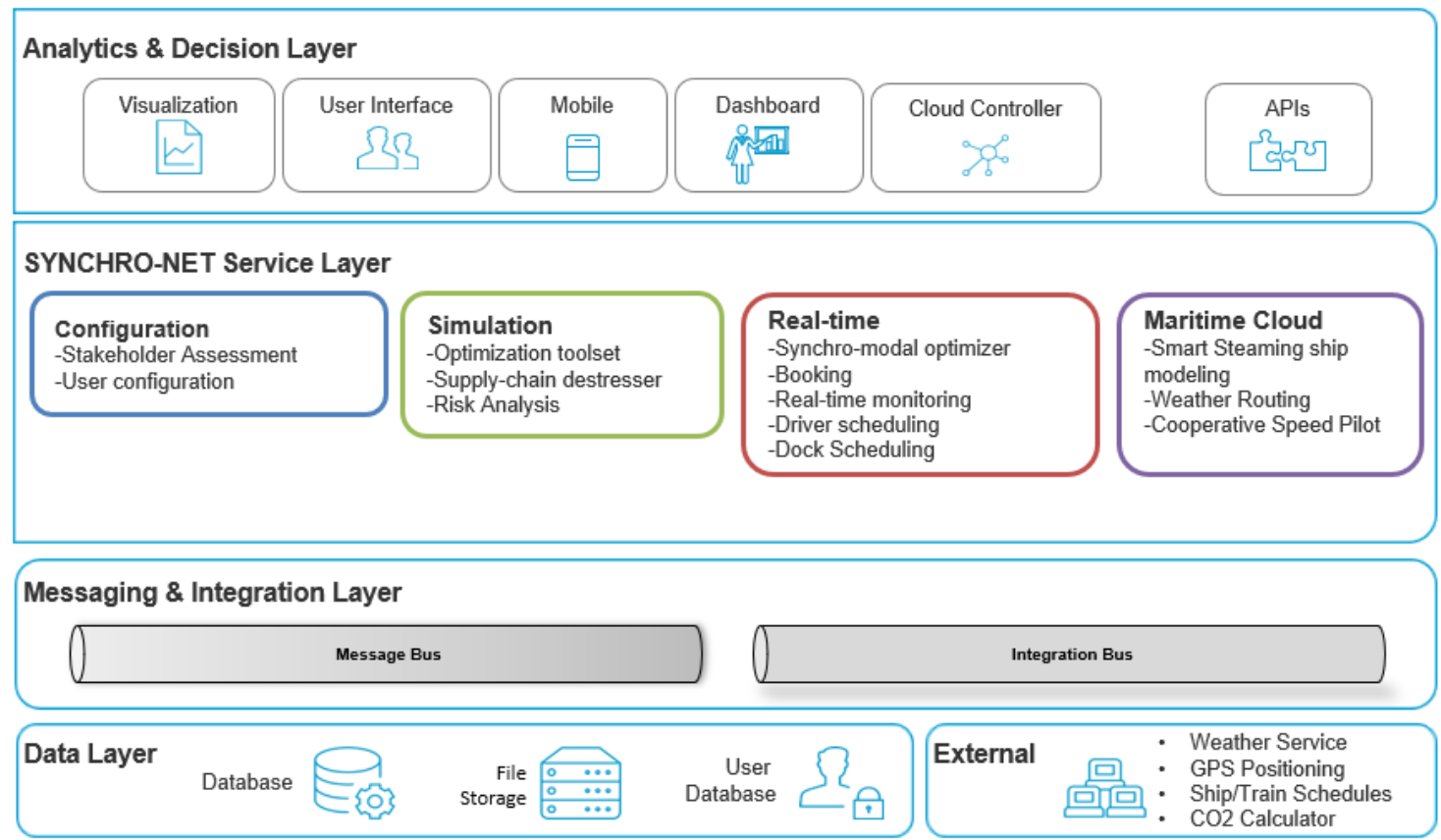

Figure 2. Layered architecture of the SYNCHRO-NET platform.

The platform can be seen as a stack-based architecture structured in four main layers. The Analytics and Decision Layer includes all the user interfacing functionalities that allow for support in decision-making (visualization, access for mobile devices, dashboard, a cloud controller to adjust the deployment of the eco-NET). Moreover, via the implemented APIs, some services will be externally accessible to allow integration into existing infrastructures. All these features are logically collected in the main framework called the SYNCHRO-NET portal (http://193.26.201.41/\#default/home, accessed: 6 November 2018), which also contains a marketplace for the APIs. The Messaging \& Integration Layer provides the technologies for message passing and integration with other services and databases, whereas the Data Layer ensures data persistence and external connections to services such as weather 
forecast, GPS positioning, emissions calculators, or other information systems (to retrieve, for instance, routes and schedules for ships and trains).

The SYNCHRO-NET Service layer represents the main functional core of the platform, hosting all the services that support and implement the project goals. As highlighted by the different colors, these services can be grouped in four main classes: Configuration, Simulation, Real-Time, and Maritime Cloud. The main software modules composing this layer, discussed in detail in the upcoming sections, are organized as shown in Figure 3.

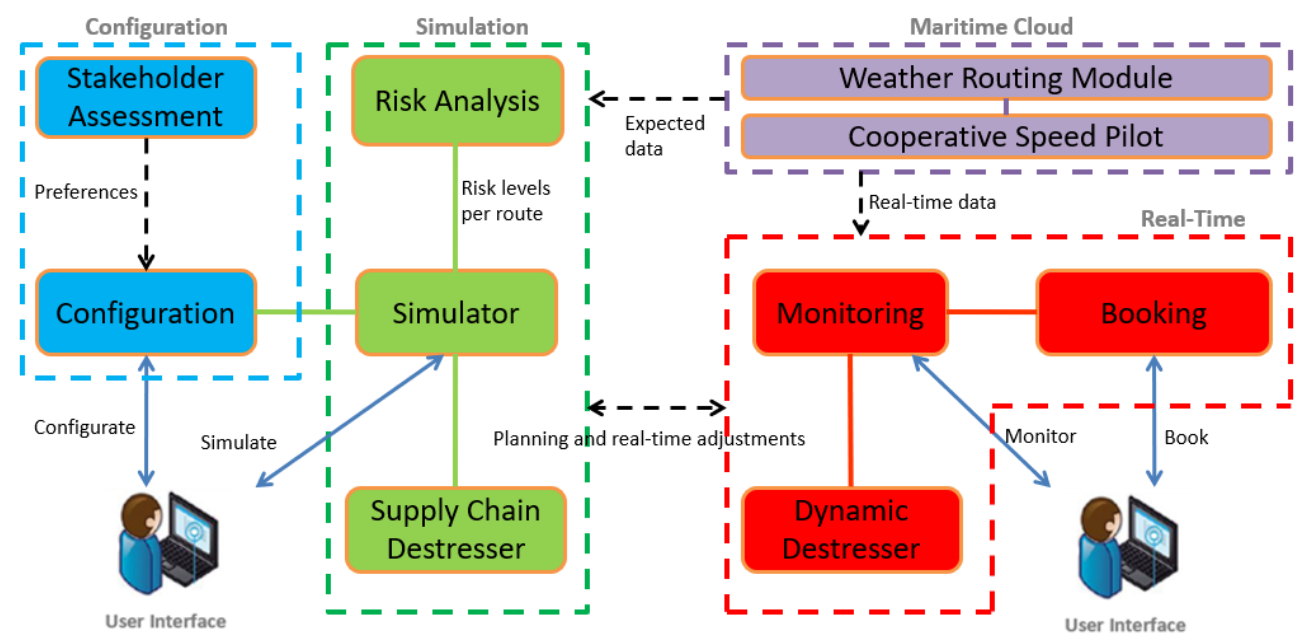

Figure 3. Functional modules and their interconnections within the eco-NET.

First, all the parameters existing in the system can be configured and tuned by the users, in order to better satisfy their needs and preferences. In particular, an elicitation procedure based on a questionnaire is provided by the Stakeholder Assessment. Then, at the strategic level, a Simulator provides an optimization engine, which, given two geographical points (an origin and a destination) and the release and due date of the cargo, returns a list of potential inter-modal routes. For each route, the actual departure and arrival times, a set of KPIs (duration, length, cost, emission), and risk indicators are also given. The simulator also interacts with a Supply Chain Destresser, which aims to encourage stakeholders to use lower risk and lower emission options. After a shipment has been booked, at the operational level, real-time tools trace the movements of the ongoing shipment and adjust the plans if some unforeseen events occur. For example, if the trip is stuck or delayed, a different route among those already provided is selected. If no route is feasible, the simulator is run again to generate a new list of potential routes from the last feasible node to the destination node using updated release time and due date. Besides this, the Dynamic Destresser actuates several operational optimization strategies for hauliers. Finally, the Maritime Cloud, through its main modules called Weather Routing and Cooperative Speed Pilot, is responsible to feed both the strategic/planning and the operational/real-time tools with maritime-related data coming from simulations and real-time monitoring, respectively.

\subsection{Synchro-Modal Strategic Optimization and Simulation Tool Set}

Within the eco-NET platform, the synchro-modal strategic optimization and simulation toolset (mainly composed by the Simulator and Supply-Chain Destresser) is responsible for providing strategic-level decision support regarding routes and schedules for synchro-modal freight transportation [17]. More precisely, by using optimization techniques and algorithms over a well-defined database of geospatial and commercial information, this tool finds the best possible solutions according to users' differing objectives and constraints, allowing for the most sustainable plans. In fact, a human planner tasked with finding the best way for moving the freight will only be able to consider a small subset of the possible options given the enormous number of available transport services and the extended 
nature of many supply chains. Moreover, in an ever-changing environment where new transport services become available every day, such a limited vision means that many opportunities for cost saving and environmental impact reduction are missed. The tool set has been developed by Politecnico di Torino, in collaboration with Syco (partners of the project). The optimization tool set uses a client-server architecture, providing a map-based web interface and REST APIs for the use by third-party applications. The system is in fact primarily conceived as a stand-alone application (mainly for advanced users) to simulate, test, and compare the outcomes of different transportation scenarios. However, the route optimization core is also extensively used by other software modules in the eco-NET to elaborate solutions (mainly, by risk analysis and real-time tools based on re-optimization).

The system is built upon an open-source package of Java libraries called OpenTripPlanner (OTP: http:/ /www.opentripplanner.org/, accessed: 4 November 2018), originally conceived as a platform for multi-modal multi-agency urban mobility planning and relied on open data standards such as Open Street Map (OSM: http:/ / www.openstreetmap.org/, accessed: 4 November 2018) for street and rail networks and General Transit Feed Specification (GTFS: http://developers.google.com/transit/gtfs/, accessed: 4 November 2018) for schedules and transits. We remark that, for the SYNCHRO-NET project, the standard OTP has been extensively customized to develop a solid and sophisticated freight transportation planner. Specific optimization procedures, new searching features, and the calculation of additional outputs have been implemented, together with specific tools to make use of them in the graphical interface. Moreover, the new system only relies on a GTFS data format extension called General Transit Feed Specification Plus (GTFS+), especially developed for the project (see Appendix A).

\subsubsection{Basic Optimization Functionalities}

The planner allows the user to select an origin and a destination for the desired shipment, and some additional constraints on departure and arrival dates/times. The locations can be selected interactively on the map or declared by inputting their name (in the latter case, the system helps the user by suggesting locations from a list of cities, harbors, and inter-modal ports already included in an auto-filling fashion). Then, the system applies efficient optimization routines and eventually returns a list of feasible multi-modal itineraries. These alternatives can be visualized on the map, together with their own summarized and detailed information (see Figure 4).

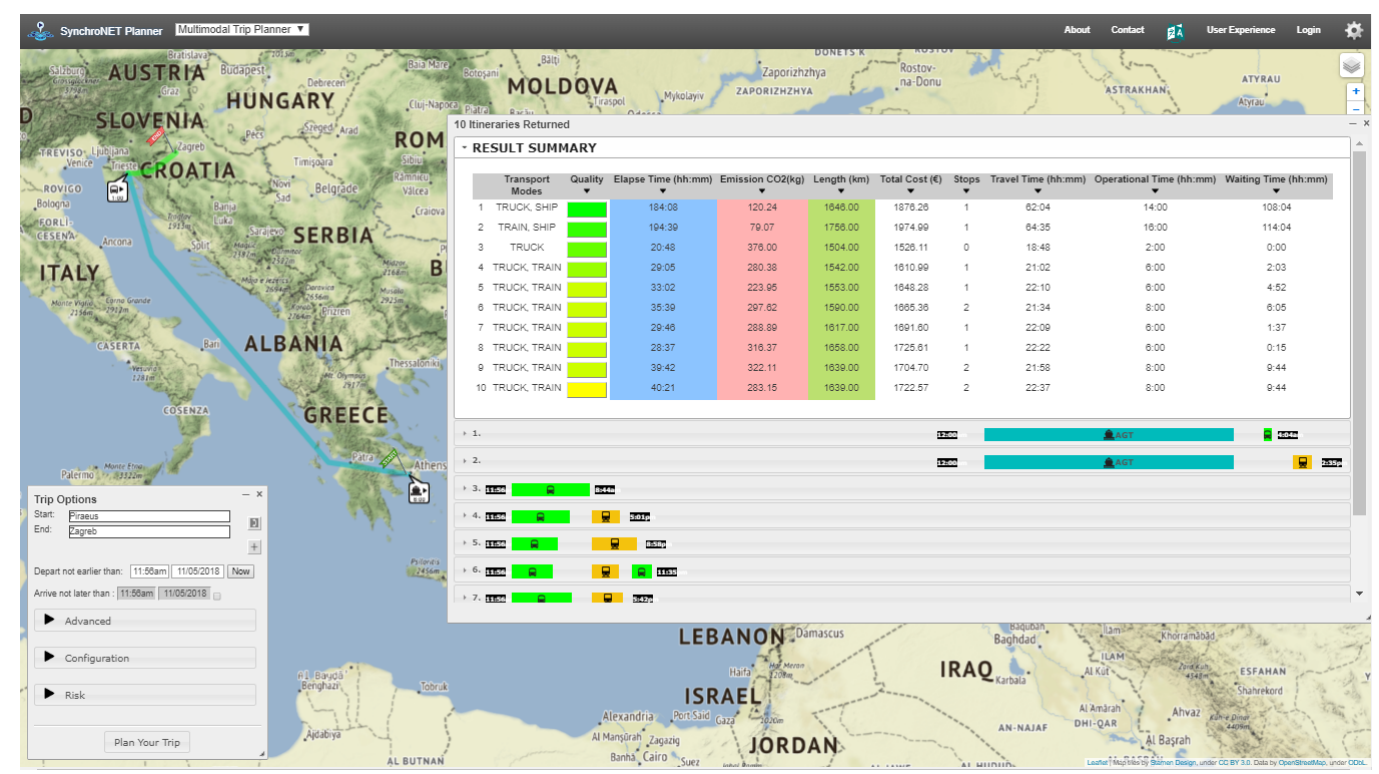

Figure 4. Returned itineraries for a shipment from the port of Piraeus (Greece) to Zagreb (Croatia). The best itinerary, represented by a feeder vessel leg from Piraeus to Rijeka (Croatia) and a truck leg from Rijeka to Zagreb, is visualized on the map. 
The summary panel is particularly useful for comparing and sorting the solutions by different quantitative values including the three main considered KPIs (elapsed time, emissions, and length), the total cost of the transportation, the types of vehicles involved, the number of stops, and some details on the time actually traveled or dedicated to waiting, boarding, and alighting. The system also attributes to each alternative a relative overall quality measure (indicated by different shades of colors from green to red). Selecting each alternative, instead, reveals more accurate details on the composing legs and their KPIs, and on the precise operational times for alighting, moving or boarding the cargo.

The efficiency in finding several alternative solutions is one of the most important added values of the SYNCHRO-NET planner. Thanks to the developed optimization routines and algorithms for routing problems $[18,19]$, the system is able to combine possible routes from a database containing hundred thousands of services and to elaborate optimal complete itineraries. In particular, given an origin and a destination point, the underlying optimization problem resorts to a variant of the well-known Shortest Path Problem (SPP), in which:

- the synchronization of the schedules among the different itinerary legs must be ensured;

- $\quad$ an inter-modal network of different transport modes (ship, barge, rail, truck) is considered;

- alighting, boarding, and transit times at each stop must be considered;

- three different objectives (i.e., the distance traveled, the time elapsed, and the $\mathrm{CO}_{2}$ emissions) must be simultaneously minimized.

Note that the resulting problem is $\mathcal{N} \mathcal{P}$-hard and, in general, the three objectives are conflicting and non-collinear. e.g., reducing the emissions by using slow-steaming navigation leads to much longer trips in terms of duration. To optimally solve the problem, a complete multi-objective approach would be prohibitive in terms of efficiency. Therefore, we opted for an adaptation of some classical exact or heuristic algorithms for the SPP such as Dijkstra and $A^{*}$ (see, e.g., [20,21]) in which a single objective function includes the three main KPIs through a weighted combination of their costs. The weights used in the objective can be configured to achieve the maximum level of flexibility (Section 4.6).

An interesting aspect to describe is how the $\mathrm{CO}_{2}$ emissions are calculated inside the Simulator. The calculation is done on a container-based granularity and takes into account both the type of vehicle and the different possible average speeds (e.g., slow or fast steaming for ships). For each leg of a shipment, the formula to calculate the relative emissions in $\mathrm{CO}_{2}$ is

$$
\mathrm{CO}_{2}[\mathrm{~kg}]:=\left(\# \operatorname{con} * \operatorname{dist}[\mathrm{km}] * \mathrm{CO}_{2}^{\text {mode }}[\mathrm{kg} / \mathrm{km}]\right) / \mathrm{Q},
$$

where \#con is the number of containers moved, $\operatorname{dist}[\mathrm{km}]$ is the distance traveled by the vehicle (in $\mathrm{km}$ ), $\mathrm{CO}_{2}^{\text {mode }}[\mathrm{kg} / \mathrm{km}]$ is a specific coefficient evaluating the emissions of $\mathrm{CO}_{2}$ per $\mathrm{km}$ and depending on the transport mode (type of vehicle and average speed), and $Q$ is the total capacity in terms of containers of the considered mode of transport (e.g., $Q=1$ for trucks). The total emissions for a complete itinerary is simply made by the summation of the emissions calculated for each composing leg. The $\mathrm{CO}_{2}^{\text {mode }}$ factor is the more complicated to calibrate and therefore its exact value comes from specific simulation tools as in the case of ships and barges (see Section 4.5) or from the knowledge of some industrial partners of the project. Obviously, this parameter is totally configurable by the user to tailor the system on its own business. We remark that the above calculation gives a good approximation of the emissions only in the case of evaluating long-haul shipments at the strategic level. Therefore, in the real-time tools dedicated to more operational phases (see Section 4.4), the emission calculation depends on other factors (e.g., in the case of last-mile logistics [22,23]).

\subsubsection{Advanced Options and Modalities}

The most important advanced search options implemented are described in the following (note that all of them can be applied simultaneously to the search): 
- mode selection: the desired subset of allowed transportation modes can be specified. The full multi-modality is set by default;

- banned routes/stops: a set of locations and/or routes which must not be part of a provided solution can be specified. This allows for simulating scenarios in which, e.g., a shipper does not want to pass through a particularly congested port or high-risk corridor;

- forced routes/stops: a set of locations and/or of routes that must be part of a provided solution can be specified. It allows for simulating scenarios in which, e.g., a shipper has the need to visit specific facilities or to use services managed by an agency with which long-term contracts exist;

- driver rest time: it is possible to take into account, within the optimized routes and schedules, also the truck drivers' rest regulation, which impacts the traveling times and the synchronization.

Furthermore, in order to assess more complex transportation scenarios, two complete advanced simulation modalities have been developed (note that the two modalities can be enabled simultaneously and are compatible with all the previous advanced search options):

- multi-destination search: in this modality, several locations can be identified as destinations of the shipment. From an optimization point of view, the system applies a plain search for each destination, stores a certain number of possible alternatives for each, and then combines them by merging common parts in a smart way. Note that the result of this process is not anymore a list of alternative itineraries but a list of complete plans (trees of itineraries) to reach all the destinations within the same shipment (see Figure 5a).

- multi-container management: in this modality, the exact number of containers to send can be declared and the system will optimize the itineraries as in the basic search but taking into account the limited capacities of the vehicles used [24]. When a vehicle is not enough for all the containers, then a new vehicle of the same type or a different mode is added to complete the shipment. The result of such a procedure (see Figure $5 b$ ) is a plan in which the exact number of containers transported by each vehicle and moved at each stop is defined, together with the number of services of the same type must be performed in parallel (e.g., how many trucks are needed).

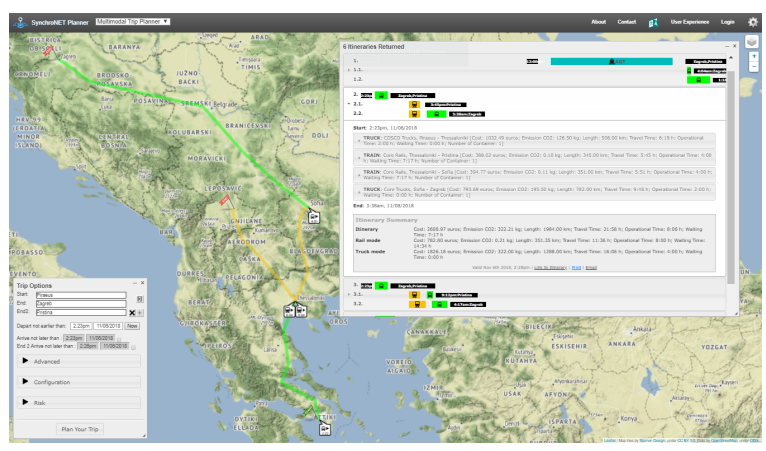

(a) Multi-destination search.

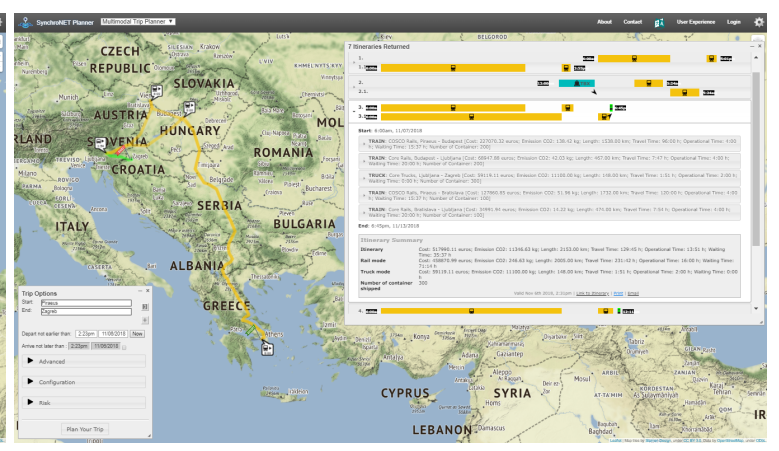

(b) Multi-container management.

Figure 5. Advanced simulation modalities.

\subsection{Simulation-Based Risk Analysis}

Within the SYNCHRO-NET platform, as just seen, alternative transportation plans are provided by the basic optimization routines to logistics operators. It is clear that, to achieve feasible and optimal solutions, the system assumes that all the data are deterministically known a priori and that the user will be able to terminate the shipment exactly as per the optimized plan. However, this is very often not the case and, therefore, other fundamental aspects such as data uncertainty and unforeseen events (delays, congestions, and accidents) should be taken into account in strategic routing optimization models and systems to offer the possibility of wiser and more robust planning decisions $[25,26]$.

In the SYNCHRO-NET project, in order to improve the reliability of the complex supply chain logistics plans and operations returned by the Simulator, additional Key Risk Indicators (KRIs) are 
provided together with the already presented KPIs by a so-called Risk Analysis Module (RAM). The RAM has been developed in collaboration with the Fraunhofer Institute for Transportation and Infrastructure Systems IVI, the partner of the project. KRIs are different aspects of the potential risks coming with each plan. To assess the risks of a specific route, existing knowledge and experience of nodes and links corresponding to this route are included in the analysis [27]. We stress the fact that the developed risk analysis follows a general approach to overcome the complexity of real synchro-modal freight transportation scenarios, and therefore it is suitable also out of the specific project scope.

As shown in Figure 6, the RAM is composed of two main components, the Risk Analysis Simulator (RAS) and the Risk Profiler (RP). The RAS receives a list of alternative optimized plans from the optimization engine of the Simulator, according to the user preferences and constraints, and returns a list of calculated KRIs through a Monte Carlo Rollout simulation. To run the simulations, RP generates random disturbances (i.e., unforeseen events that affect the regular schedule or the transportation path) for each link of a plan, based on available historical data. To this aim, existing knowledge on ports' and links' congestion is of fundamental importance for the robustness of the analysis. These data are collected during past routes' executions in the so-called historical storage. The described RAM has been implemented directly into the SYNCHRO-NET Strategic Optimization toolset (described in Section 4.2) by means of specific open-source Java libraries for statistical analysis.

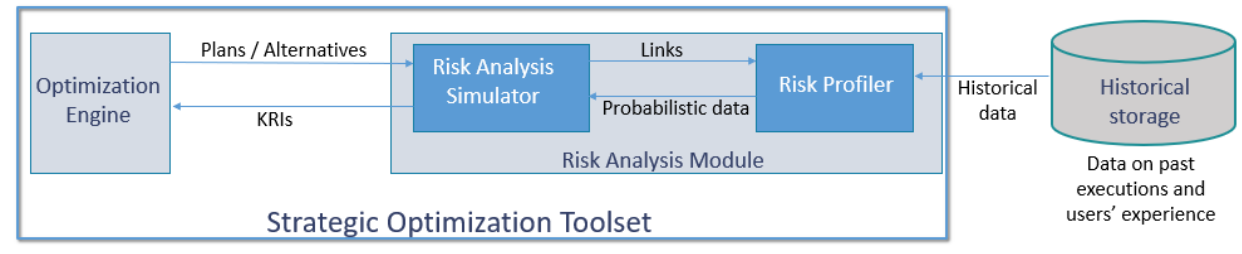

Figure 6. Risk Analysis Module structure and interactions.

\section{Monte Carlo Rollout Simulation Approach}

The RAM implements a simulation-based algorithm called Monte Carlo Rollout [28]. A schematic overview of this procedure is shown in Figure 7. In this approach, a so-called random player generates path disturbances and delays on each input alternative (i.e., each different transportation plan), then a so-called decision maker checks if each plan is still feasible or not after being afflicted by each disturbance. If the analyzed plan results in not being feasible anymore for a certain disturbance (e.g., if the cargo is not ready in a specific port to be boarded for the next transportation link due to time delay in the previous one), RAS sends new requests to the optimization engine of the Simulator to adapt the plan to the new unexpected conditions (e.g., new time constraints may be added to manage the delay). For each alternative, this simulation procedure iteratively continues (by recording the resulting cost and time for adaption) until the final desired destination is reached.

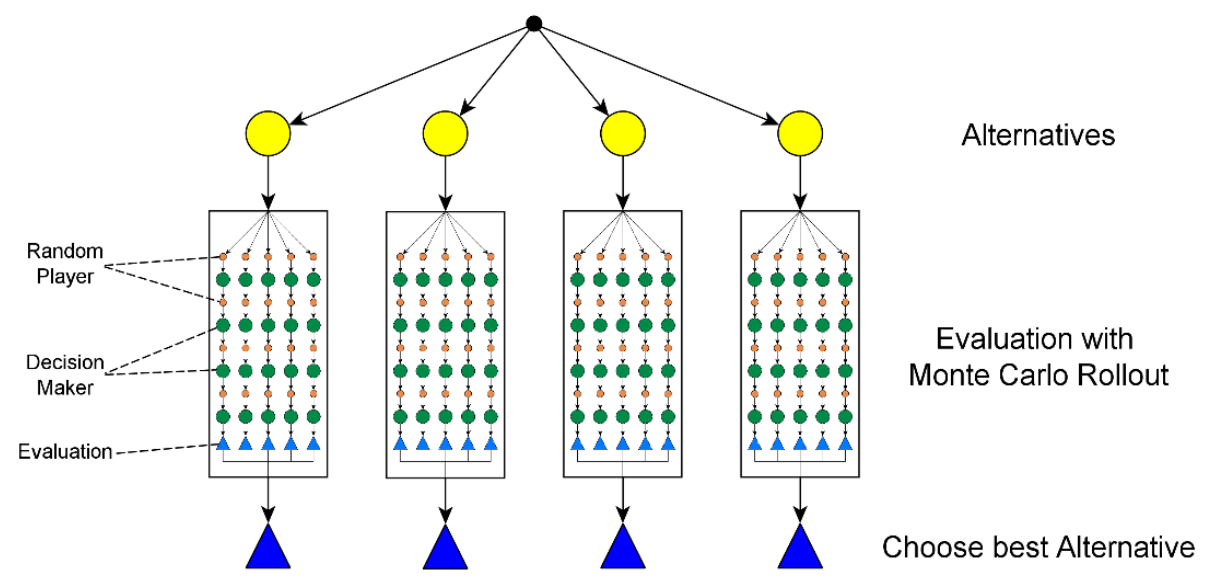

Figure 7. Schematic overview of the Monte Carlo Rollout approach. 
Since in our system the quantity and the precision of available historical data are not known a priori, we have considered two main cases for the generation of the random disturbances:

- there is not enough historical data: different initial distribution functions (chosen according to experience) are used to generate random numbers for disturbances. To simulate a path disturbance (such as works in progress along a road), we use the Bernoulli distribution to generate a random number between 0 and 1 . If that number is less than 0.05 , it means that the path will be actually changed and a new plan, using a different path, will be considered for adaption. For simulating a time disturbance, instead, we use different distribution functions for the three different transportation modes considered. These distributions are centered on an expected value for the possible delay. e.g., for truck movements, we use a Normal distribution centered around the value 20 (i.e., we have higher tendency to generate the number 20) since it is quite consolidated that the average time delay is 20 min every 200 min of trip;

- historical data are enough for a robust simulation: we sample random disturbances and their values from the most relevant historical data, by using some machine-learning feature selection techniques to select its most discriminative property. For instance, concerning the transportation of goods through the Irish sea, the season seems the most discriminative property (since in winter there are probably larger and more frequent time delays than in summer).

The output of the Monte Carlo Rollout approach described above is represented by four main KRIs, calculated for each itinerary or transportation plan:

- Flexibility: is the average time spent for adaption. All the time deriving from the waiting of new suitable movements, in the case of misses, is summed up and averaged over all simulations;

- Safety: we first calculate how many times the accident occurred on a route; then, the rate of occurrence is achieved by dividing by the total execution times. The final safety value is calculated by using 100 to subtract the happening rate;

- Time deviation: is the average time deviation with respect to the expected one. It sums up all the time deviations occurred in the risk simulations, and then achieves the averaged number by dividing by the total number of the risk simulations;

- Cost deviation: is the difference between the planned cost and the executed cost in the simulation. The executed cost is the total cost of all the executed links and the cost due to disturbances.

The resulting KRIs are shown along with other KPIs (cost, time, and emission) and plotted in a bar chart. For each KRI, a bar indicates the average value (normalized in the range [0, 100]) from the simulation runs. Additionally, a tooltip shows the standard deviation, the minimum and maximum value of the indicator over the runs. This way, the decision-maker obtains an easy-to-use tool to compare alternative plans not only based on traditional KPIs but also considering possible consequences of real-time disturbances and adaptive actions. Moreover, the module enables selecting the best transportation plan according to the personal risk aversion or affinity. In fact, a general risk rating is also calculated as a weighted function of the four main KRIs (useful to rank the alternative plans with respect to a common scale). During the plan optimization phase, the user can specify the value of those weights according to the importance he gives to the different KRIs (Section 4.6).

\subsection{Real-Time Optimization Tool Set}

Real-time supply chain information has been made more readily available by the recent advances in data exchange and sharing technologies. For example, many Automatic Identification Systems (AIS) such as marinetraffic.com and several port community systems can provide nowadays real-time visibility of shipping movements via APIs. Again, Global Navigation Satellite Systems (GNSS) are able to provide real-time truck and train positional data, while ERP systems allow real-time status updates about transport orders and resource availability. For these reasons, besides the strategic optimization tool set, the SYNCHRO-NET platform provides other fundamental modules for the management 
of freight transportation and the support of the decision at operation/real-time level in a complex synchro-modal environment. These tools have been developed by $M J C^{2}$ Limited, partner of the project.

\subsubsection{Monitoring and Re-Optimization Features}

One of the most important features provided by the SYNCHRO-NET solution is the use of real-time data feeds to detect serious deviations from the plan, and consequently to support the planner in finding the best alternatives or corrections to implement. For example, a delay of a shipping movement triggers an automatic re-optimization to find a new solution which is still cost-effective, environmentally friendly, and allows the goods to arrive on time. The re-optimization is performed by a sophisticated procedure that iteratively calls for the optimization engine of the Simulator, setting the current adjusted searching options, and validate the results against the available real-time information. Despite the complexity of such a task, SYNCHRO-NET is able to re-plan container movements in seconds (offering true real-time decision support).

The ability to automatically reschedule the movements clearly increases the robustness of the supply chain. However, in the SYNCHRO-NET approach, possible operational issues are considered since the very initial strategic planning. In fact, with the help of the system and its indicators, users are more likely to choose a more complex but greener and more flexible route if they are confident that the impact in terms of costs and times of potential issues can be mitigated in real time.

\subsubsection{Real-Time Destressing and Operations Optimization}

Besides its re-optimization capabilities, the SYNCHRO-NET system primarily tries to avoid issues at an operational level such as queuing and congestion happening at logistics terminals. Despite different strategies adopted by many terminals (e.g., slot booking systems), many opportunities still exist to further de-stress busy ports by smart load distribution and resource utilization planning. The SYNCHRO-NET project exploits these opportunities by including into the platform several software modules able to perform real-time haulier optimization routines, reducing costs and congestion at the port. The optimization framework is based on several main strategies, described in the following:

- dynamic equipment re-use: the total number of in/out movements from/to a terminal can be reduced by selecting the appropriate combinations of import and export movements, thus limiting total truck costs, emissions and Kms;

- arrivals balancing: in order to smooth the profile of truck movements at the hubs, it is possible to exploit the availability flexibility in arrival and departure times for container movements. For example, empty containers repositioning, in general less urgent than export shipments, may have more flexibility to be scheduled in the next time-slots;

- driver hours optimization: using availability flexibility in arrival time windows again, it is possible to smartly combine long-haul and short-distance movements, allocating more, but better distributed, loads to drivers.

Again, to achieve all these benefits, it is necessary to couple the real-time de-stressing procedures with the synchro-modal logistics optimization engine, making the entire supply chain more robust.

\subsection{The Maritime Cloud}

The so-called Maritime Cloud is an aggregation of several software modules developed within the SYNCHRO-NET project specifically designed to deal with the maritime-side of freight transportation and logistics. These modules have been developed by the Centre de Recherche pour l'Architecture et l'Industrie (C.R.A.I.N.), Kongsberg Maritime, SAM Electronics, and HydrOcean, under the coordination of Bureau Veritas (all partners of the project). The main role of this integrated cloud is to provide expected and real-time information for the optimization routines implemented into the strategic Supply-Chain Destresser and into the Real-Time Destresser, respectively. Moreover, it provides the 
necessary communication interfaces between the SYNCHRO-NET real-time monitoring systems and the instrumentations onboard the ships. A simplified version of the architecture of the Maritime Cloud is shown in Figure 8, where input and output for the main modules are highlighted.

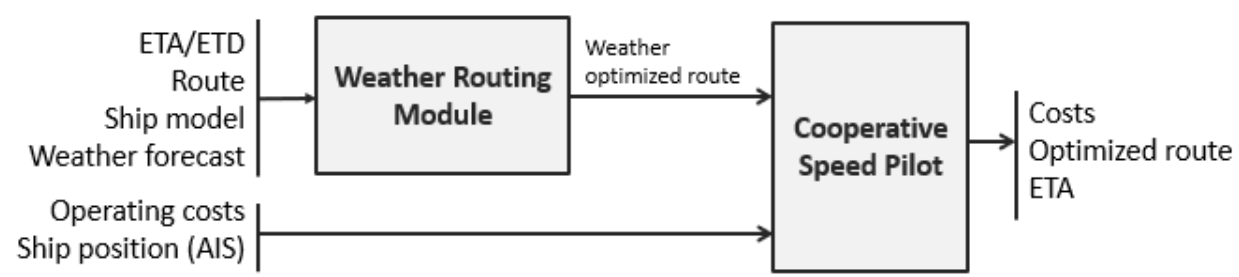

Figure 8. Input/output of the Maritime Cloud modules.

The core of the process starts with an energy model-based simulation of several different types of cargo ships (in terms of weight, dimension, capacity, etc.), engined by different types of steaming. We remark that the exploitation of smart-steaming strategies into long-haul transportation is one of the main objectives of the SYNCHRO-NET project. The Ship Energy Modeling tool is aimed at the calculation of the fuel consumption of a ship and the associated emissions, taking into account all the energy consumers and producers onboard the ship (hull resistance, electrical consumers, main engines, diesel generators, waste heat recovery, and oil-fired boilers). The ship energy model developed for this project is based on Ship Energy Efficiency Calculation and Analysis Tool (SEECAT) solution proposed in [29]. Even if at a higher level of the platform, only the $\mathrm{CO}_{2}$ emissions are evaluated, and the described module is able to derive the assessment of several different pollutants, like $\mathrm{NO}_{\mathrm{x}}$ and $\mathrm{SO}_{\mathrm{x}}$, and even the amount of fuel consumption in different phases of the navigation.

The output of the above simulation, together with some information about a precise route (Expected Time of Departure/Expected Time of Arrival plus its expected trajectory) and weather forecast for that particular journey, composes the input for the so-called Weather Routing Module (WRM). The main objectives of the WRM are the assessment and the optimization (in terms of consumption, speed, and other parameters) of the considered route by taking advantages of weather conditions on the specified trip. The WRM output can be different depending on whether the data generation is for strategic or real-time/operational optimization. In the former case, the assessment is done by using historical weather data and eventually the WRM returns the main route KPIs, fuel consumption, and different type of emissions metrics in GTFS+ format (see Appendix A). In the latter case, instead, the assessment includes weather forecast and the output is the optimized route as per the operational objectives (minimization of duration, length, and emissions) in the classical Route Exchange (RTZ) format. Furthermore, the WRM also provides some output to feed the risk analysis (Section 4.3), such as margin on ETAs or measures on the eventuality of adverse weather conditions.

Finally, the Cooperative Speed Pilot (CSP) is designed to calculate optimal speed profiles for a given ship voyage such that the overall costs are minimized. Such costs can be seen both as expenses for the ship owner or for the shipping agency that hires the ship. It receives as input the weather optimized routes in RTZ format and, possibly, updated ETA and AIS data on the actual ship position. The outputs are detailed operating costs to reach the final destination and a new route in RTZ format, with optimized speed to achieve the new ETA. Moreover, hydrodynamic curves for the sailing ship are also returned. The CSP is used for planning, monitoring, and calculating speed reference for an actual ship in transit and can operate in three main functional modes:

- $\quad$ strategic mode: an external system requests to compute a cost estimate based on a planned sailing route. The route describes a voyage between two ports and is already optimized for weather conditions along the planned route. The route and rate data are given as input parameters to the web-service, which will return calculated cost values; 
- operational mode: a sailing ship requests to be optimized in terms of speed and cost for the remaining part of the route. The route and rate data is given as input parameters to the web-service, which will return its optimized values based on current ship position along the route to the next port. The returned route may contain modified ETA and speed values due to given constraints related to time and rates. The ship may evaluate the result and consider changing ship speed as advised;

- schedule mode: similar to operational mode, but the actual route data will not be modified. The request refers to a sailing ship route in operation and alternative ETAs, speeds and rates may be used to see consequences in cost.

\subsection{User Authentication, Configuration, and Stakeholder Assessment}

It is clear that the SYNCHRO-NET solution can be useful for several different actors and stakeholders in the supply chain, such as retailers, freight forwarders, ship operators, real-time ship managers, and port authorities. Hence, different types of users might approach the platform with possibly very different needs, duties, and perspectives. For this reason, a classical authentication and accounting framework has been developed around the system, and specific functionalities are enabled or disabled depending on the user role or permissions.

Most importantly, recognizing a user allows the platform to provide full configuration potentialities for a powerful exploitation and customization of the functionalities of the system. For example, in the Simulator, all the global parameters used inside the optimization procedures to evaluate the KPIs of the solutions can be set to specific values. These parameters include:

- proportional costs per kilometers, per hour, or per $\mathrm{kg}$ of $\mathrm{CO}_{2}$, for each type of vehicle;

- average speed of each in-land transport mode and each type of steaming;

- capacities of the vehicles;

- alighting, boarding and other operational times at logistics facilities for each vehicle or type of loading such as Roll-On/Roll-Off (RoRo) or Load-On/Load-Off (LoLo).

Obviously, this is useful to simulate very realistic or customized scenarios and to keep the system updated with respect to market and technology changes.

Of particular interest is the ability to control the extent to which the three main KPIs, i.e., the length, the duration, and the emissions of a solution, affect the optimization (triangular tool on the left side of Figure 9). The same weighting is possible among the four main KRIs, i.e., safety, flexibility, time and cost reliability (see the circular tool in the right side of Figure 9). The combination of percentage weights used reflects, for example, the needs of a specific scenario or the preferences of a specific user.

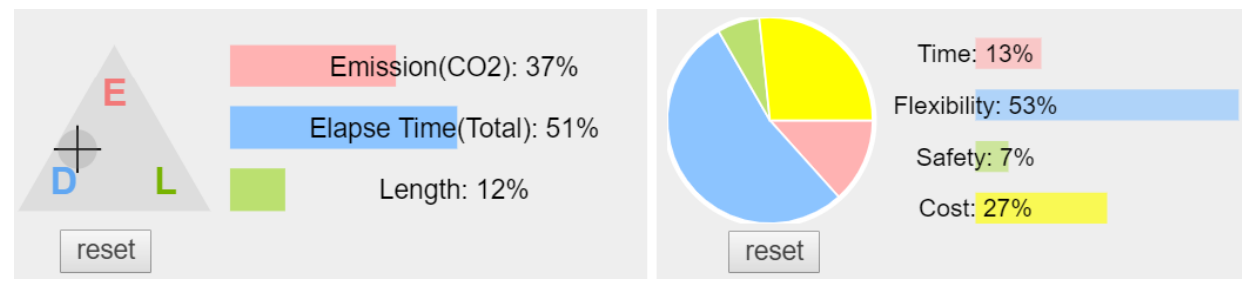

Figure 9. Relative weights adjustment for KPIs and KRIs.

Finally, it is important to remark that the system supports the user's simulations by providing complete configuration and management functions, to create, store, load, edit, and delete them. This is enabled through the development of a MYSQL database and link with the SYNCHRO-NET tool set.

All the previous presented configurations are supposed to be implemented manually by a user. However, to really exploit a human-centric stakeholder-driven approach, a semi-automatic procedure based on eliciting methods has been developed. The procedure, called Stakeholder Assessment (SA), can be enabled by compiling a quick online multi-choice questionnaire that asks a user about its qualitative 
evaluation of several factors and situations concerning freight transportation scenarios. From the questionnaire outputs, the system is able to derive quantitative values representing, in particular, the proportions among the KPIs and KRIs weights, automatically creating and storing a tailored configuration. SA has been developed by London Economics, partner of the project.

To support different possible use-cases of the system, the SA operates under two main modalities:

- offline: this process is aimed at profiling user categories and, therefore, the system needs to harvest, store, and analyze data coming from several questionnaires in order to create the KPIs/KRIs. Here, the data are stored in a well-formatted text file, one for each category. Average values of KPIs and KRIs for each user category are calculated and sent periodically (e.g., once a day) to the Simulator, to be used as default values for each specific user type;

- online: this process is aimed instead at profiling a specific user (potentially a new one), in order to configure the Simulator according to her/his preferences. Specific APIs allow an automatic communication of those data in real time.

\section{Case-Studies and Experimental Results}

Three full business-case, namely the East-West Trade Lane, the Pan European, and the Regional demonstrators, have been defined and implemented to evaluate benefits of the SYNCHRO-NET solution in terms of technical feasibility, sustainability, and practicability. The demonstrators have different scopes and objectives, as described in Section 5.1, and have contributed to derive the results presented in Section 5.2.

The first two demonstrators have been guided by COSCO SHIPPING Lines (Spain) S.A., while the third one is tailored for the Kuehne+Nagel (Ireland) business and has been implemented in collaboration with the Cork Institute of Technology (NMCI) and EMC Information Systems International. To support the three demonstrators, the system has been fed with a large set of realistic routes and schedules for different types of vehicles. Truck, rail, and ship routes linking thousands of main cities, harbors and inter-modal ports have been stored along with their schedules and frequencies (see Appendix A). Where possible, geo-spatial data have been automatically extracted from Geographical Information Systems, whereas commercial details (schedules, times, and costs) have been given by the above demonstrator leaders and by other involved companies (DHL Spain and Rail Safety and Standards Board). All the mentioned bodies/companies are partners of the SYNCHRO-NET project.

\subsection{Demonstrators and Scenarios}

The East-West Trade Lane demonstrator aims to test the SYNCHRO-NET platform to optimize import and export operations between the Far East and the inland destinations in Spain, through the three main Spanish ports of Valencia, Barcelona, and Algeciras (see Figure 10a). Specifically, the main objective is to improve shipping and hinterland logistics operations along the entire supply chain, by testing two main scenarios:

- ship route planning optimization, to evaluate the ability of the maritime cloud to implement smart steaming potential in order to adopt a new ship's route and speed in response to port delays or bad weather;

- inland transport planning optimization, to test the real-time tool set to optimize hinterland transport planning by increasing modal shift to rail and saving empty movements by maximizing re-use and back-hauling opportunities.

The Pan European demonstrator aims to optimize freight flows from the Far East to the Central Europe and Balkans through Piraeus Hub (see Figure 10b). It focuses on two scenarios:

- assessment of transport options and quotations, by testing the synchro-modal planning tool set and the simulation-based risk analysis which provide a decision support at the strategic level during 
the preparation of quotations in order to identify the preferred multi-modal route that meets the customers' requirements in terms of the balance between cost vs. emissions vs. risk vs. duration;

- synchro-modal planning and scheduling, by implementing the real-time optimization tool set which provides decision support at the operational level to book and track in progress actual customer orders and corresponding movements and re-plan the route in response to real-time events caused by weather, congestion, or other delays that might affect the shipment.

The Regional demonstrator has the objective to increase container traffics from Little Island (Ireland) to Germany through the regional port of Cork (see Figure 10c). The synchro-modal planning tool set and the simulation-based risk analysis have been implemented to support two main scenarios:

- customer cumulative freight transport weight and volume optimization, to increase the overall efficiency of a customer supply chain by optimizing volumes involved in individual shipments and reducing the number of shipments over, e.g., one year;

- modal shift from RORO land bridge to LOLO direct to/from mainland Europe, to foster a modal shift to LOLO direct services to Germany across the Northern European ports.

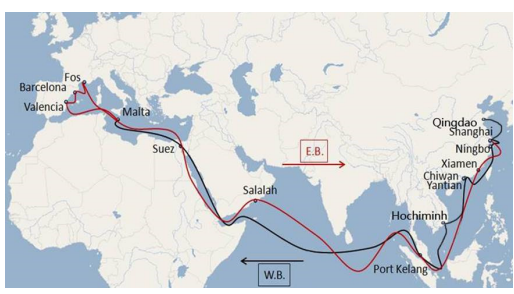

(a) East-West Trade Lane.

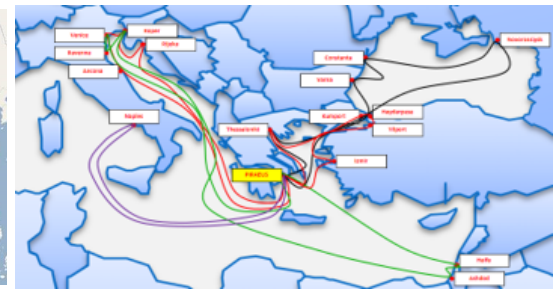

(b) Pan European demonstrator.

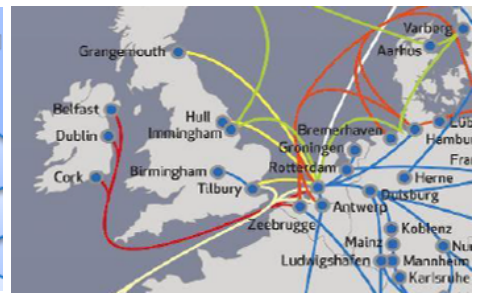

(c) Regional demonstrator.

Figure 10. SYNCHRO-NET real-case demonstrators and their scope.

\subsection{Results and Discussion}

In the East-West Trade Lane demonstrator, the Maritime Cloud modules have optimized the speed of oceanic ships in order to better synchronize the arrivals with the transit capacities, whereas the real-time optimization toolset has been able to address the complex multimodal operations from the land side, optimizing connectivity between the ports and the customers. Interesting enough, the real-time optimization algorithms have driven a substantial modal shift from truck to rail. Furthermore, the last-mile truck operations have also been optimized in an integrated way, showing significant reductions in terms of kilometers and driver hours, while maximizing re-use and back-hauling opportunities. Tests performed in the East-West demonstrator have shown a 9\% increase in rail and $7 \%$ potentiality in implementing import/export pairings, with a consequently $23 \%$ reduction in kilometers traveled by truck, $15 \%$ decrease of $\mathrm{CO}_{2}$ emission, and $15 \%$ reduction in transportation costs.

In the Pan European demonstrator, the end-to-end process has been covered from the strategic planning of shipping routes up to the real-time synchro-modal execution of the multi-modal transport plan. The availability of a synchro-modal strategic optimization and simulation and of simulation-based risk analysis has allowed exploring feasible synchro-modal alternatives in accordance with customer's requirements. The tests performed have demonstrated the possibility to identify optimal multi-modal transportation solutions and itineraries with a balanced measure of emissions, costs, and length. Tests have shown the possibility to implement feasible synchro-modal solutions allowing a $14 \%$ reduction of $\mathrm{CO}_{2}$ emissions. At an operational level, the real-time optimization tool set has demonstrated benefits in monitoring shipments in progress by detecting delays and automatically finding new alternative routing, reducing or eliminating the delay on arrival time of the goods to the customer while being cost-effective and environmentally friendly. Furthermore, the system has allowed for planning the allocation of the containers to the right wagon of a train, taking into account 
operational constraints, as well as to optimize slots on ocean vessels by dynamically responding to potential real-time events.

Again, the synchro-modal planning tool set and the simulation-based risk analysis have been tested to compare alternatives, not only analyzing KPIs but also considering KRIs. Results from the Regional demonstrator have shown that the implemented risk analysis can provide additional values in identifying robust multi-modal solutions, giving to the decision maker more dimensions to quantify the overall quality of the chosen solutions. The system has also achieved a high level of flexibility and configurability, this way allowing different users with different needs (and interests) to configure the parameters of the search. Even if a precise configuration can be manually implemented in the system, the possibility to achieve a working configuration through a semi-automatic process (the Stakeholder Assessment) has been evaluated as extremely useful and time-saving from the testers.

In conclusion, the three described demonstrators have tested the potential of the SYNCHRO-NET eco-NET platform to cover an end-to-end shipping process, from the strategic planning of shipments to their real-time synchro-modal execution. SYNCHRO-NET, in fact, supports the identification of the preferred multi-modal routes that meets customers' requirements in terms of balanced features (emissions, costs, duration, length, risk), the booking of the real shipment, and the tracking of the route in progress (in order to detect possible real-time events affecting the shipment and automatically finds an alternative routing). It is worthwhile noting that the eco-NET platform provides to the user, through the implementation of cloud concepts, a unique seamless system to deal with logistics processes. Finally, the platform ensures consistency and security of data and results, which is definitely a strict requirement for each company involved in this kind of business.

We want to remark that the developed demonstrators and the relative scenarios have been specifically conceived to show that the SYNCHRO-NET approach can cope with different scales, sizes, and complexity of the freight transportation process. The tests have been run by considering different geographical areas, with ports of different size and routes of different length, and synchronizing vehicles with the most diverse features in terms of capacity, speed, and flexibility. The platform has shown good performances when facing long-haul shipments through the very wide East West corridor from China to Spain (with the aim to optimize both shipping and hinterland operations and reduce costs and GHG emissions), when considering the Orient/East-Med corridor that connects central Europe with ports of North, Baltic, Black, and Mediterranean seas, and, finally, when the scope has been reduced to a regional level to understand how to overcome the complexity of the Irish supply chain affected by different local issues.

\subsection{Impact on Sustainability}

As expected, the SYNCHRO-NET approach shows a non-marginal impact in terms of sustainability of the freight transportation process and, more in general, of the international supply-chains. On average, it can achieve $15-20 \%$ of potential decrease of $\mathrm{CO}_{2}$ emissions, while maintaining sustainable transportation costs for the logistics operators. At the same time, the approach seems able to improve the transportation service performance in terms of timing and robustness to disruptions. These achievements depend on a mix of peculiar factors, directly or indirectly impacting on sustainability:

- exploitation of slow/smart steaming strategies: the project first addresses the use of innovative energy models and smart steaming piloting of the ships. Substantial savings in terms of fuel from shipping can be achieved by using the Maritime Cloud modules, especially for cases where the ship encounters bad weather or port delays. For example, results from the East-West Trade Lane demonstrator show a reduction of fuel consumption between $7 \%$ and $28 \%$ with a corresponding reduction of $\mathrm{GHG}\left(\mathrm{CO}_{2}, \mathrm{NO}_{\mathrm{x}}, \mathrm{SO}_{\mathrm{x}}\right)$ emissions;

- optimization capabilities (at planning and real-time phase) also exploiting synchromodality: a complex process as the freight transportation can be approached only by an integrated vision and the implementation of efficient and effective optimization procedures able to find the best solutions 
to apply (in terms of scheduling, routing, facility, and capacity usage decisions). e.g, the East-West demonstrator highlights the SYNCHRO-NET ability to de-stress the global supply chain in an integrated way, from the optimization of the ocean-going vessel to the reduction of fuel costs of last-mile operations from the port to customers. Moreover, the innovative synchro-modal concept allows for obtaining a high grade of flexibility and robustness. For instance, in the Regional demonstrator, delays in maritime services and stresses in the supply chain have a direct effect on time and costs of transport operations due to Ireland's geographical position. Here, SYNCHRO-NET is configured to optimize freight flows from Ireland to main North European harbours and cities, by highlighting new opportunities reducing costs and GHG emissions;

- stakeholder-driven decision support system to exploit greener alternatives with quantification of the impacts: the synchro-modal platform developed can support the user to take more informed decisions about the freight movements, by analyzing a large set of KPIs such as costs, durations, and emissions and KRIs. This allows for comparing different alternatives and selecting the best on a case by case basis, rather than always deciding on the cheapest. For example, a much greener option may be available against a small increase in cost, which would be missed if cost was the only parameter used. For example, in the Pan European demonstrator, SYNCHRO-NET shows how to de-stress the supply chain and reduce costs and emissions by taking advantage of the intra-Europe services, including feeder services along the Adriatic, Aegean, and Black Sea and the railway network, and keeping truck movements only for the last mile. Also in the Regional demonstrator, the flexibility of the alternative solutions proposed allows for simulating and re-optimizing the Irish supply chains considering new geo-political constraints, e.g., possible future scenarios after Brexit.

A further interesting outcome of the project lies in the opportunity to use the resulting tools by the logistics providers for green certification of their activities. In fact, according to the technical specification ISO/TS 14067:2013 "Greenhouse gases-Carbon footprint of product-Requirements and guidelines for quantification and communication," it is possible to define the carbon footprint (i.e., the total amount of GHG emitted directly or indirectly) of an activity as the freight transportation process or of a company working in that field. Apart from a clear return in terms of image (e.g., for a logistics operator), this may foster a mental shift of the involved actors, which is fundamental for a sustainable future of the international supply chains.

\section{Lessons Learned, Threads and Opportunities}

The SYNCHRO-NET project has shown how synchro-modality and slow-steaming can be effective solutions in developing freight delivery services sustainable from the different point of view (operational, economic, environmental). In particular, it is clear how the definition of freight corridors should be carefully planned for implementing a better usage of the logistics network and the supply chains. Moreover, the interaction in the project of a huge number of stakeholders highlights the necessity of fostering the cooperation of the different actors (senders, shippers, 3PLs, facility managers, public and private authorities). In this section, we analyze the possible barriers to the introduction of SYNCHRO-NET as a business reality and the opportunities for future developments.

\subsection{Legal Issues}

The presence of different regulations concerning technical and administrative aspects, as well as the coexistence of different standards, can act as a limiting factor for business exploitation of SYNCHRO-NET. In fact, the optimization tools should be modified in order to consider, in a modular way, the legal constraints that might occur while creating a potential synchro-modal corridor. This aspect becomes more and more important while considering the increasing freight coming from or shipped to countries in other continental areas. The plethora of documents that must be produced 
during the shipment due to different local interpretations of the standards must be integrated into SYNCHRO-NET in order to push the different actors to a factual usage of the tool.

\subsection{Data Sharing}

The logistics sector is a complex system made by a network of stakeholders and actors with different and often conflicting objectives, which must cooperate anyway to reach common benefits [30]. Ecosystems like SYNCHRO-NET strongly rely on the sharing of data among the actors and the system is mainly accessible by users through an authentication page. The SYNCHRO-NET tool will provide the user with his personal data, including the weights he assigned for the KPIs and KRIs, the historical data on the previously selected transport solutions, and private information such as shipping costs. However, this is not enough to foster a real collaboration between potential users. There is a need for the creation of a technology infrastructure able to support the data sharing while preserving data integrity, security and, for some information, privacy. The infrastructure should be decentralized, in order to remove the barriers of many logistics operators due to giving a third-party company or organization their industrial information. Moreover, the booking process and the cost negotiation should be automatized so that eventual conflicts in terms of access to limited resources (for example, a specific warehouse) would be managed in an automated way by the system. All those considerations bring us to consider as a possible opportunity an upgrade of the SYNCHRO-NET system with the introduction of a BIC (Blockchain-Internet of Things-Cloud) technology layer [31].

The Blockchain technology can be defined as a distributed ledger database for recording transactions between parties verifiable and permanently. The Blockchain is a disruptive innovation, due to its capability of ensuring data immutability and public accessibility of data streams. Moreover, its decentralized and distributed infrastructure prevents the problems of the present centralized approaches, including trust issues, such as fraud, corruption, tampering and falsifying information, and their limited resiliency. It can foster the trust between the actors by ensuring the data immutability, while the decentralized nature of the Blockchain overcomes the fear of third-party management of the data. Moreover, its capability to incorporate secured automated procedure (the so-called Smart Contract) makes it easier to integrate the Blockchain with legacy and existing systems, as well as to incorporate verified booking and cost negotiations procedures.

As previously said, another crucial point for synchro-modal transportation is the data gathering. It is needed not only to have a clear vision of the status of the logistics network but also to prevent potential problems thanks to process analytics. The possible answer to this need comes from the Internet of Things (IoT) paradigm. Several definitions can be given of an IoT system, but, for our purposes, the better one of the definition of an IoT as a system for making physical entities to collaborate through their connection to a common and public data network. The different physical entities can make use of the shared information from other entities and processes to independently control logistics and production systems [32]. Recently, it was showed how the integration of IoT and Blockchain could increase the efficiency of the Blockchain while increasing the security level and reducing the overall management cost [33]. Moreover, the massive presence of sensors and intelligence in the facilities and the vehicles used in the logistics and shipment operations would make its integration less costly, while supporting the overall optimization process [34].

Finally, all the services and the infrastructure must be cloud-based, in order to improve the scalability and the availability of the different services.

\subsection{Future Exploitation}

Besides the potential constraints highlighted above, the results of SYNCHRO-NET can be hopefully transferred out of the project dimension into the market. The future exploitation relies on a mix of business and technology factors.

From a management point of view, this approach should foster cooperation among operators, under the regulation of the authorities. To the present time, the actors do not clearly see by themselves 
the benefits of such an integration, while the regulations do not create the necessary terrain for the creation of new business models. On the contrary, the on-demand economy, with the consequent change from an offer-driven to a demand-driven logistics, is reducing margins of the operators drastically, while imposing higher quality standards in the management of the supply chain. Those issues, if not considered and governed, might bring to a business war between the different actors and under utilization of the infrastructures, as already shown in the urban logistics [35,36]. In order to foster this change, there is the need for introducing a certification of the residual capacity present in the network, as well as a clear and transparent negotiation mechanism of the costs and the quality of service. Moreover, the overall exploitation process should take into account the lessons learned from the startup failures, by adopting a lean business approach [37] and by fostering the trust between the different actors through the decentralization and securitization of the data and a capacity reservation process based on a Blockchain infrastructure [31].

From a more technical point of view, it is also possible to identify a large number of key exploitable results. In practice, the SYNCHRO-NET platform being an ecosystem in which different modules (with different objectives and targeting different types of users) cooperate and exchange information in order to provide optimal transport solutions, it is possible to individually exploit each of them (e.g., the booking module, the simulation and optimization toolset, the risk analysis module, etc.). This is not a marginal aspect, since it creates the possibility to modularly customize the system into a commercial solution suitable for different types of business, needs, and development phases of the re-engineering process of logistics operators towards synchro-modality. Finally, we also comment on the fact that some modules (e.g., the Simulator, the Risk Analysis, and the GTFS+ format) have been publicly released under open-source licenses. This aims at fostering new applications and scientific outputs outside the specific project, both in industrial and academic environments.

\section{Conclusions}

The SYNCHRO-NET solution conceived and implemented something unique in its field. Its vision and guiding business model, coming from a strict interaction with several stakeholders, foster a more sustainable world-wide future freight commerce. The business model analysis provides a managerial perspective that facilitates the market acceptance of SYNCHRO-NET, as well as the economic sustainability of the project in the long run.

The developed platform represents a major step forwards in logistics optimization capability (since it models the integrated supply chain, including all modes and related activities), and pursues a more sophisticated de-stressing approach which considers several cost voices, environmental impact, risks, and other factors. The system allows:

- at a strategic level, to find the best multi-modal routes and schedules to move freight, by analysing the relative risk indicators;

- at an operational level, to enable the dynamic switching of that solution in response to real-time events (exploiting synchro-modality concepts).

The so-called Maritime Cloud is able to leverage the use of slow/smart steaming practices inside the platform functionalities, demonstrating potentialities at strategic and operational levels. Finally, to support decisions in an ever-changing environment as the one of freight transportation, the entire system achieved a high level of flexibility and configurability through the Stakeholder Assessment approach and several other facilities. In particular, analyzing the stakeholders requirements helps to develop a solution that meets their needs.

The proposed SYNCHRO-NET solution was tested by implementing three real-case demonstrators with different scopes and scales. In particular, we considered pan-European and regional trade lanes, as well as commercial activities between Far East and European ports. The overall platform provided efficiency and effectiveness in supporting decisions and, not less important, achieved a high grade of automation in several processes to overcome the main issues related to human-based operations. 
Finally, the demonstrators showed the strong benefits for sustainability derived from a smart adoption of synchro-modality and slow-steaming concepts within the supply-chains to de-stress congestions and optimize resources and shipments.

We also analyzed possible barriers and opportunities of the approach, industrial and academic developments, and relations with emerging technologies. Besides the factors that could potentially hinder the implementation of the SYNCHRO-NET approach out of the project scope, it is interesting to highlight how the strength of the proposed solution relies on a powerful mix of business and technological factors.

We conclude our work by sketching some possible improvements that would be useful to study and implement after the end of the project itself. Given the complexity of freight transportation logistics, many new features can be embedded in the optimization process, both at strategic and operational levels. For example, cargo incompatibility [38,39], loading constraints [40], or more sophisticated pricing functions involving e.g., quantity discounts [41-43] can be considered as well. Moreover, other state-of-the-art communication standards and protocols can be addressed to make the platform even easier to integrate and interface with existing information systems, databases, and other operative tools. Finally, the experiments reported in Section 5 show that the developed risk analysis gives additional values in supporting robust routing and scheduling decisions for synchro-modal freight transportation. However, up to today, KRIs are calculated only a posteriori with respect to the plan optimization. A possible future research could be about integrating risk attributes directly into the optimization procedures.

Author Contributions: Conceptualization: D.M., G.P., and R.T. Software development: R.G., Y.L., and S.Y. Data validation: C.I., D.M., and S.M. Supervision and project administration: R.T. All the authors have contributed to writing and reviewing the paper.

Funding: Funding for this work was provided by the SYNCHRO-NET project, H2020-EU.3.4.-Societal Challenges -Smart, Green and Integrated Transport, Ref. 636354.

Acknowledgments: The authors are sincerely grateful to all the partners of the SYNCHRO-NET project whose effort has been fundamental for the good success of the project itself, allowing for achieving the results presented in this contribution. The paper is dedicated to the memory of Philippe Corrignan, from Bureau Veritas (Paris, France), who originally coordinated the maritime partners of the project and sadly passed away in October 2018.

Conflicts of Interest: The authors declare no conflict of interest. The funding sponsors had no role in the design of the study; in the collection, analyses, or interpretation of data; in the writing of the manuscript, and in the decision to publish the results.

\section{Abbreviations}

The following abbreviations are used in this manuscript:

$\begin{array}{ll}\text { API } & \text { Application Programming Interface } \\ \text { AIS } & \text { Automatic Identification Systems } \\ \text { ETA } & \text { Expected Time of Arrival } \\ \text { ETD } & \text { Expected Time of Departure } \\ \text { CSP } & \text { Cooperative Speed Pilot } \\ \text { GHG } & \text { Green-House Gas } \\ \text { GNSS } & \text { Global Navigation Satellite Systems } \\ \text { GPS } & \text { Global Positioning System } \\ \text { GTFS } & \text { General Transit Feed Specification } \\ \text { ICT } & \text { Information and Communications Technology } \\ \text { IoT } & \text { Internet of Things } \\ \text { KPI } & \text { Key Performance Indicator } \\ \text { KRI } & \text { Key Risk Indicator } \\ \text { LOLO } & \text { Load-On/Load-Off } \\ \text { OSM } & \text { Open Street Map } \\ \text { OTP } & \text { OpenTripPlanner }\end{array}$




$\begin{array}{ll}\text { RAM } & \text { Risk Analysis Module } \\ \text { RAS } & \text { Risk Analysis Simulator } \\ \text { RP } & \text { Risk Profiler } \\ \text { REST } & \text { Representational State Transfer architecture } \\ \text { RORO } & \text { Roll-On/Roll-Off } \\ \text { RTZ } & \text { Route Exchange } \\ \text { SA } & \text { Stakeholder Assessment } \\ \text { SEECAT } & \text { Ship Energy Efficiency Calculation and Analysis Tool } \\ \text { SOA } & \text { Service-Oriented Architecture } \\ \text { SPP } & \text { Shortest Path Problem } \\ \text { SYNCHRO-NET } & \text { SYNCHRO-modal supply chain eco-NET } \\ \text { TEU } & \text { Twenty-foot Equivalent Unit } \\ \text { WRM } & \text { Weather Routing Module } \\ \text { WTO } & \text { World Trade Organization }\end{array}$

\section{Appendix A GTFS+: A New Standard Data Format for Freight Logistics}

The original GTFS format has been conceived to deal with public transportation schedules and agencies, mainly at an urban level, and therefore it can not support the developed container-based freight transportation and logistics planner. In order to simplify the information management and standardize the interaction between SYNCHRO-NET internal modules and their users, we have decided to create GTFS+, a new standard data format specifically designed for freight logistics. The adoption of the GTFS+ format, in particular, has been fundamental to speed up the system response with respect to the standard OTP, in order to be able to deal with real-time environments. The new standard has been developed by Politecnico di Torino, in collaboration with Cross-Border Research Association (partners of the project).

It is not possible to provide here an extensive treatment of the GTFS+ format; therefore, we will just summarize the innovative features. The new specifications are intended to follow the native GTFS philosophy, in order to minimize the future adaptation of already existing GTFS tools. In particular, the GTFS format has been extended to include only the geospatial information needed (e.g., length and shape of a route, country and typology of a location), commercial and operational information about the routes (monetary contract costs, vehicle type, loading type, times for boarding, alighting and movement of containers).

We also remark that the system provides two important tools to facilitate the creation and the updating of GTFS+ data inside the Simulator, i.e., the GTFS+ generator and the GTFS+ editor:

- The GTFS+ generator is a batch procedure that, given a list of locations (as the ones in Figure A1a), automatically generates a database of GTFS+ routes (see Figure A1b) by combining OSM information and standard commercial features. More precisely, for each pair of locations, the tool returns (if they exist) unimodal truck and train routes corresponding to the shortest path in terms of geographical distance, generates the corresponding GTFS+ data, and stores them into the system database.

Since the set of generated routes grows quadratically with the locations number, we have implemented a clustering algorithm and a two-tier generation of the routes to reduce the GTFS+ database size. More precisely, we cluster around the biggest locations (centroids) all those ones (satellites) located within a given radius. Then, only centroids are used for the above complete generation, while each satellite is linked with similar routes only to its own centroid.

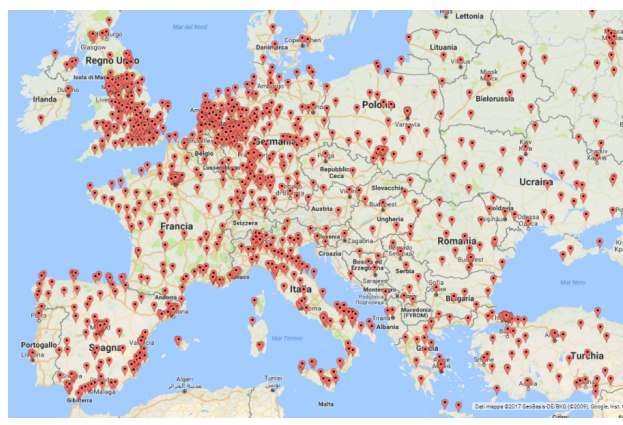

(a) Main European locations.

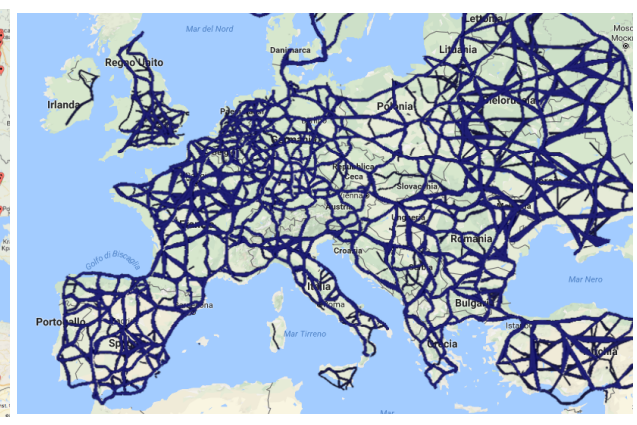

(b) European truck and rail routes.

Figure A1. Main European routes automatically generated and stored into the system.

We remark that ship and vessel routes are not created through this tool, but they are fed to the Simulator by the Maritime Cloud (see Section 4.5). 
- The GTFS+ editor consists in a series of interactive and map-based interfaces that allow the user to add and modify locations of interest and all the connecting routes (together with their schedules, geo-spatial, and commercial information) into the system database. The editor can correctly handle writing operations on GTFS+ data according to the different users and, therefore, a user can operate only on its own GTFS+ data without damaging the entire database consistency. The editor is obviously designed to reflect the GTFS+ data structure and to include the new features described above. It consists of three main parts:

- $\quad$ stop editor: it allows the user to modify the existing locations and define the desired ones if they are not yet available in the database by giving names and coordinates or selecting them directly on the map. Extra information, including country, type of the location, role in the network (centroid or satellite) can be assigned to the stop as well;

route editor: it manages the creation of the new routes and the modification of the existing ones. Many fields can be specified, i.e., the mode of the route, the service dates where the route is valid, departure and arrival time, the number of days between the departure and arrival dates (in case of long period routes that exceed one-day duration), and the frequency, if any, with which the route is repeated after a time interval (e.g., every two hours). Finally, a specific interactive editor is devoted to the way points indicate the shape of the route (see Figure A2);

- $\quad$ service editor: it is devoted to arranging the schedules. A schedule is composed of a periodic weekly calendar and a set of separate dates that represent exceptions to the calendar. The calendar is created by selecting the days of the week where the service operates repetitively. Two types of exceptions can be defined, i.e., including a date that does not appear in the periodic weekly calendar or excluding a date that is active.

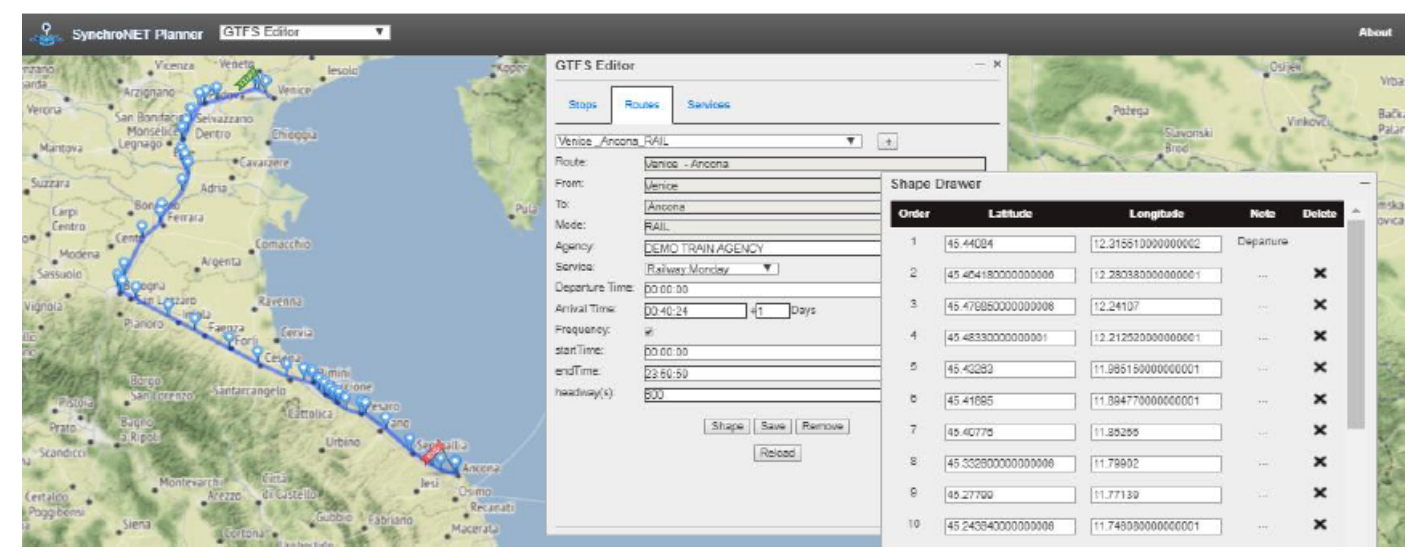

Figure A2. An example of the GTFS+ editor, in which a rail route from Venice to Ancona (Italy) is under editing. The left panel contains general information about the route and its schedules, while the right panel can be used to define or modify the geographical shape of the route (coordinates of the way points).

\section{References}

1. World Trade Organization. Trade Recovery Expected in 2017 and 2018, Amid Policy Uncertainty. 2017. Available online: https://www.wto.org/english/news_e/pres17_e/pr791_e.htm (accessed on 8 December 2018).

2. United Nations Conference on Trade and Development (UNCTAD). Review of Maritime Transport 2015; UNCTAD: New York, NY, USA; Geneva, Switzerland, 2015.

3. EUROSTAT. Road Freight Transport by Journey Characteristics. EUROSTAT Statistics Explained Series. 2016. Available online: https:/ / ec.europa.eu/eurostat/statistics-explained/index.php/Road_freight_transport_ by_journey_characteristics (accessed on 1 February 2019).

4. Centobelli, P.; Cerchione, R.; Esposito, E. Environmental sustainability in the service industry of transportation and logistics service providers: Systematic literature review and research directions. Transp. Res. Part D Trans. Environ. 2017, 53, 454-470. [CrossRef]

5. Bonney, J. Carriers Move Full Speed Into Slow Steaming. 2010. Available online: http://www.joc.com/ maritime/carriers-move-full-speed-slow-steaming (accessed on 1 February 2019).

6. Lee, C.Y.; Lee, H.; Zhang, J. The impact of slow ocean steaming on delivery reliability and fuel consumption. Transp. Res. Part E 2015, 76, 176-190. [CrossRef] 
7. Pfoser, S.; Treiblmaier, H.; Schauer, O. Critical Success Factors of Synchromodality: Results from a Case Study and Literature Review. Transp. Res. Procedia 2016, 14, 1463-1471. [CrossRef]

8. Woodburn, A. An analysis of rail freight operational efficiency and mode share in the British port-hinterland container market. Transp. Res. Part D Transp. Environ. 2017, 51, 190-202. [CrossRef]

9. Sureeyatanapas, P.; Poophiukhok, P.; Pathumnakul, S. Green initiatives for logistics service providers: An investigation of antecedent factors and the contributions to corporate goals. J. Clean. Prod. 2018, 191, 1-14. [CrossRef]

10. Palmer, A.; Mortimer, P.; Greening, P.; Piecyk, M.; Dadhich, P. A cost and $\mathrm{CO}_{2}$ comparison of using trains and higher capacity trucks when UK FMCG companies collaborate. Transp. Res. Part D Transp. Environ. 2018, 58, 94-107. [CrossRef]

11. Ambra, T.; Caris, A.; Macharis, C. Towards freight transport system unification: Reviewing and combining the advancements in the physical internet and synchromodal transport research. Int. J. Prod. Res. 2018, 1-18. [CrossRef]

12. ALICE. Alliance for Logistics Innovation through Collaboration in Europe Web Site. 2017. Available online: http:/ / www.etp-logistics.eu (accessed on 8 December 2018).

13. Perboli, G.; Musso, S.; Rosano, M.; Tadei, R.; Godel, M. Synchro-Modality and Slow Steaming: New Business Perspectives in Freight Transportation. Sustainability 2017, 9, 1843. [CrossRef]

14. Mes, M.; Iacob, M. Synchromodal Transport Planning at a Logistics Service Provider. In Logistics and Supply Chain Innovation: Bridging the Gap between Theory and Practice; Lecture notes in logistics; Zijm, H., Klumpp, M., Clausen, U., ten Hompel, M., Eds.; Springer: Cham, Switzerland, 2016; pp. 23-36.

15. Kapetanis, G.N.; Psaraftis, H.N.; Spyrou, D. A Simple Synchro-Modal Decision Support Tool for the Piraeus Container Terminal. Transp. Res. Procedia 2016, 14, 2860-2869. [CrossRef]

16. Holfeld, D.; Iorfida, C.; Koya, M.; Manerba, D.; Stephens, J.; Tadei, R.; Werner, F. SYNCHRO-NET: A powerful and innovative synchro-modal supply chain eco-NET. In Proceedings of the TRA 2018-7th Transport Research Arena, Vienna, Austria, 16-19 April 2018.

17. Giusti, R.; Manerba, D.; Perboli, G.; Tadei, R.; Yuan, S. A New Open-source System for Strategic Freight Logistics Planning: The SYNCHRO-NET Optimization Tools. Transp. Res. Procedia 2018, 30, $245-254$. [CrossRef]

18. Manerba, D.; Mansini, R.; Riera-Ledesma, J. The Traveling Purchaser Problem and its Variants. Eur. J. Oper. Res. 2017, 259, 1-18. [CrossRef]

19. Toth, P.; Vigo, D. Vehicle Routing: Problems, Methods, and Applications, 2nd ed.; MOS-SIAM Series on Optimization; Society for Industrial and Applied Mathematics: Philadelphia, PA, USA, 2014.

20. Festa, P. Shortest Path Algorithms; Springer: Boston, MA, USA, 2006; pp. 185-210. [CrossRef]

21. Hart, P.E.; Nilsson, N.J.; Raphael, B. A Formal Basis for the Heuristic Determination of Minimum Cost Paths. IEEE Trans. Syst. Sci. Cybern. 1968, 4, 100-107. [CrossRef]

22. Perboli, G.; Rosano, M. Parcel delivery in urban areas: Opportunities and threats for the mix of traditional and green business models. Trans. Res. Part C Emerg. Technol. 2019, 99, 19-36. [CrossRef]

23. Manerba, D.; Mansini, R.; Zanotti, R. Attended Home Delivery: Reducing last-mile environmental impact by changing customer habits. IFAC-PapersOnLine 2018, 51, 55-60. [CrossRef]

24. Baldi, M.M.; Manerba, D.; Perboli, G.; Tadei, R. A generalized bin packing problem for parcel delivery in last-mile logistics. Eur. J. Oper. Res. 2019, in press. [CrossRef]

25. Beraldi, P.; Bruni, M.E.; Manerba, D.; Mansini, R. A stochastic programming approach for the traveling purchaser problem. IMA J. Manag. Math. 2017, 28, 41-63. [CrossRef]

26. Manerba, D.; Mansini, R.; Perboli, G. The Capacitated Supplier Selection problem with Total Quantity Discount policy and Activation Costs under uncertainty. Int. J. Prod. Econ. 2018, 198, 119-132. [CrossRef]

27. Holfeld, D.; Simroth, A.; Li, Y.; Manerba, D.; Tadei, R. Risk Analysis for synchro-modal freight transportation: the SYNCHRO-NET approach. In Proceedings of the ODYSSEUS 2018-7th International Workshop on Freight Transportation and Logistics, Cagliari, Italy, 3-8 June 2018.

28. Simroth, A.; Holfeld, D.; Tadei, R. Risk Analysis for a Synchro-modal supply chain. In Proceedings of the 28th European Conference on Operational Research (EURO2016), Poznam, Poland, 3-6 June 2016. 
29. Marty, P.; Corrignan, P.; Gondet, A.; Chenouard, R.; Hétet, J.F. Modelling of energy flows and fuel consumption on board ships: Application to a large modern cruise vessel and comparison with sea monitoring data. In Proceedings of the 11th International Marine Design Conference, Glasgow, UK, 11-14 June 2012; Volume 3, pp. 545-563.

30. Crainic, T.G.; Perboli, G.; Rosano, M. Simulation of intermodal freight transportation systems: A taxonomy. Eur. J. Oper. Res. 2018, 270, 401-418. [CrossRef]

31. Perboli, G.; Musso, S.; Rosano, M. Blockchain in Logistics and Supply Chain: A Lean Approach for Designing Real-World Use Cases. IEEE Access 2018, 6, 62018-62028. [CrossRef]

32. Minerva, R.; Biru, A.; Rotondi, D. Towards a Definition of the Internet of Things (IoT). IEEE Report. IEEE Internet Initiative, 2015. Available online: https://iot.ieee.org/images/files/pdf/IEEE_IoT_Towards_ Definition_Internet_of_Things_Revision1_27MAY15.pdf (accessed on 1 February 2019).

33. Sliman, L.; Dellys, H. Security, safety and confidentiality in iot for collaborative business technologies (SSCIoT track of WETICE 2018). In Proceedings of the 2018 IEEE 27th International Conference on Enabling Technologies: Infrastructure for Collaborative Enterprises (WETICE), Paris, France, 27-29 June 2018; pp. 181-186. [CrossRef]

34. Fadda, E.; Gobbato, L.; Perboli, G.; Rosano, M.; Tadei, R. Waste collection in urban areas: A case study. Interfaces 2018, 48, 307-322. [CrossRef]

35. Perboli, G.; Rosano, M.; Saint-Guillain, M.; Rizzo, P. Simulation-optimisation framework for City Logistics: an application on multimodal last-mile delivery. IET Intell. Transp. Syst. 2018, 12, 262-269. [CrossRef]

36. Perboli, G.; Rosano, M.; Gobbato, L. Decision support system for collaborative freight transportation management: A tool for mixing traditional and green logistics. In Proceedings of the ILS 2016-6th International Conference on Information Systems, Logistics and Supply Chain, Bordeaux, France, 1-4 June 2016.

37. Cantamessa, M.; Gatteschi, V.; Perboli, G.; Rosano, M. Startups' roads to failure. Sustainability 2018, 10, 2346. [CrossRef]

38. Manerba, D.; Mansini, R. The Nurse Routing Problem with Workload Constraints and Incompatible Services. IFAC-PapersOnLine 2016, 49, 1192-1197. [CrossRef]

39. Gendreau, M.; Manerba, D.; Mansini, R. The Multi-Vehicle Traveling Purchaser Problem with Pairwise Incompatibility Constraints and Unitary Demands: A Branch-and-Price Approach. Eur. J. Oper. Res. 2016, 248, 50-71. [CrossRef]

40. Iori, M.; Martello, S. Routing problems with loading constraints. TOP 2010, 18, 4-27. [CrossRef]

41. Manerba, D.; Perboli, G. New solution approaches for the capacitated supplier selection problem with total quantity discount and activation costs under demand uncertainty. Comput. Oper. Res. 2019, 101, $29-42$. [CrossRef]

42. Manerba, D.; Mansini, R. An exact algorithm for the Capacitated Total Quantity Discount Problem. Eur. J. Oper. Res. 2012, 222, 287-300. [CrossRef]

43. Manerba, D.; Mansini, R. An effective matheuristic for the capacitated total quantity discount problem. Comput. Oper. Res. 2014, 41, 1-11. [CrossRef]

(C) 2019 by the authors. Licensee MDPI, Basel, Switzerland. This article is an open access article distributed under the terms and conditions of the Creative Commons Attribution (CC BY) license (http://creativecommons.org/licenses/by/4.0/). 